\title{
On the conservative behavior of biomass water productivity
}

\author{
Pasquale Steduto - Theodore C. Hsiao • \\ Elìas Fereres
}

Received: 4 November 2006/ Accepted: 4 January 2007 / Published online: 2 February 2007

(C) Springer-Verlag 2007

\begin{abstract}
The ever-increasing demand and competition for the finite water resource worldwide call for more efficient use of water in all sectors, including firstly agricultural food production. One important consideration is the existence of a limit to the amount of biomass a crop can produce per unit of water consumed. This article analyzes the theoretical background and the experimental evidence for the conservative behavior of the efficiency in water use by crops to produce biomass, i.e., biomass water productivity $\left(\mathrm{WP}_{\mathrm{b}}\right)$, under variable environmental conditions. Particularly, $\mathrm{WP}_{\mathrm{b}}$ is approximately constant for a given crop species after normalization for evaporative demand of the atmosphere and air carbon dioxide concentration. A stepwise scaling up approach, from leaf to canopy, is undertaken to underline the processes involved at the different hierarchical levels of biological organization that lead to the conservative behavior of $\mathrm{WP}_{\mathrm{b}}$. Starting at the leaf level, the basic gas exchange equations are outlined to demonstrate that the normalized photosynthetic $\mathrm{WP}_{\mathrm{b}}$ at the leaf scale is proportional to the ambient $\mathrm{CO}_{2}$ concentration. New
\end{abstract}

Communicated by R. Evans.

P. Steduto $(\square)$

Division of Land and Water, FAO,

United Nations, viale delle Terme di Caracalla,

00153 Rome, Italy

e-mail: pasquale.steduto@fao.org

T. C. Hsiao

Department of Land, Air and Water Resources,

University of California, Davis, CA, USA

E. Fereres

IAS-CSIC and University of Cordoba, Cordoba, Spain experimental evidence in support of that conclusion is presented for several $\mathrm{C}_{3}$ and a $\mathrm{C}_{4}$ crops. Additional factors are introduced to assess photosynthetic $\mathrm{WP}_{\mathrm{b}}$ at the canopy scale, including the extent of radiation capture and the role of respiration. The composition of biomass was then considered in the analysis of $\mathrm{WP}_{\mathrm{b}}$ over a season. The paper highlights the need to normalize $\mathrm{WP}_{\mathrm{b}}$ for differences in climate, specifically, in evaporative demand of the atmosphere to extrapolate $\mathrm{WP}_{\mathrm{b}}$ values between climatic zones, and in atmospheric $\mathrm{CO}_{2}$ concentration to account for changes in $\mathrm{CO}_{2}$ with time, when looking at the past and into the future. Two procedures for normalization for differences in evaporative demand are presented, and a procedure for normalization for changes in $\mathrm{CO}_{2}$ concentration is derived for the leaf scale and shown to be applicable to canopy scale. Some knowledge gaps and research needs are pointed out and the potential offered by the near constancy of normalized $\mathrm{WP}_{\mathrm{b}}$ in crop simulation modeling is emphasized.

\section{Introduction and background}

Food production and water use are two closely linked processes. As the competition for water intensifies worldwide, water in food production must be used more efficiently. Of the different steps in water use in the crop production process, the most fundamental is the exchange of water lost by transpiration for the assimilation of carbon dioxide. The net gain of carbon and energy by the plant in this process then leads to the production of biomass, of which the harvested yield is usually only a part. It turns out that for biomass 
production, the efficiency of water use (transpiration) is relatively constant after the variation in two key environmental factors, evaporative demand of the atmosphere and air carbon dioxide concentration, are accounted for by normalization.

This conservative behavior has been analyzed and discussed in detail several times in the past half century. In light of the urgent need to answer the question of just how much the efficiency of water use in agriculture can be improved, we are revisiting the issue here, to examine the theoretical basis for the conservative behavior, to evaluate just how conservative biomass water productivity is, and to consider the possibility of its improvement. The conceptual basis for the conservative behavior will be reviewed, recent data evaluated and discussed, and the different ways to normalize for evaporative demand and carbon dioxide concentration illustrated. It is hoped that this discourse will help to focus better the potential means to improve the efficiency of water use, and also lead to the modeling of crop productivity based on water use. The subject of this paper, biomass water productivity, is a segment in the sequence of steps in the use of water for crop production. The broader aspects of the efficiencies in agriculture include many other efficiency steps, and these are considered in another paper in this special issue (Hsiao et al. 2007).

Biological or primary productivity is normally evaluated in terms of biomass (as dry matter), and the water consumed and not recoverable in this production process is normally assessed in terms of evapotranspiration (ET), the sum of transpiration by the crop (T) and evaporation from the soil (E). This paper focuses on the production of biomass in relation to transpiration. Only the water transpired is considered because evaporation from the soil is not in exchange for carbon assimilated. Here biomass water productivity $\left(\mathrm{WP}_{\mathrm{b}}\right)$ is defined as the aboveground dry matter ( $\mathrm{g}$ or $\mathrm{kg}$ ) produced per unit land area $\left(\mathrm{m}^{2}\right.$ or ha) per unit of water transpired $\left(\mathrm{mm}\right.$ or $\left.\mathrm{m}^{3}\right)$. The units of $\mathrm{WP}_{\mathrm{b}}$ are then either $\mathrm{kg} \mathrm{m}^{-3}$ or $\mathrm{kg} \mathrm{ha}^{-1} \mathrm{~mm}^{-1}$. In the literature water productivity is mostly expressed as the ratio of biomass to evapotranspired water, because separation of $\mathrm{E}$ from $\mathrm{T}$ was not possible in these cases. Although the units remain the same regardless whether $\mathrm{T}$ or ET is the denominator, it is important to specify which water productivity is being referred to.

The scales considered here range from individual leaves up to crop plant communities, with the boundary conditions for the latter being that of an agricultural field. Only above-ground biomass is considered, even though root biomass is a reasonably significant component of total biomass and a fraction of daily photosynthate is allocated to the growth and maintenance of the root system (Lambers 1987). The very limited information on root biomass in relation to water use, relative to that existing on shoot biomass, made it necessary to restrict this analysis to shoot biomass production. Fortunately, for most crop species except root crops, only a small portion of the total biomass is in roots so that considerable changes in root biomass may occur with only minor effect on total biomass. Relative to shoot, root growth is known to be more resistant to nutrient and water deficiencies (Taylor 1983; Hsiao and Xu 2000a). On the other hand, there is a homeostatic growth response toward a near constant root:shoot ratio (Brouwer 1983).

Water productivity is also referred to as water use efficiency (WUE) in the literature. Monteith (1984, 1993) criticized the WUE term and pointed out that no theoretical limits exist as reference, as it should be for efficiency in an engineering sense. On the other hand, efficiency is used widely in economics without a theoretical maximum. More practically, the extensive use of WUE had caused confusion and met objections mainly because the meaning of the term depends on the specifics of the numerator and denominator defining it. This problem can be overcome by specifying with subscripts, as exemplified in Hsiao et al. (2007).

Many experiments have shown that the relationship between biomass produced and water consumed by a given species is highly linear. This indicates that $\mathrm{WP}_{\mathrm{b}}$ is approximately constant, a feature that is critical for the analyses of water-limited productivity. The linearity between crop biomass (and often final yield) and water use has been observed since the early 1900 (e.g., Briggs and Shantz 1913a, b), although the first analytical approach to formalize the relationship was developed by de Wit (1958). Several hundreds of linear relationships can be found in the literature (e.g., Hanks 1983) along with different approaches to link both variables (e.g., Arkley 1963; Bierhuizen and Slatyer 1965; Stewart 1972; Hanks 1974; Stanhill 1986). Tanner and Sinclair (1983) presented a systematic analysis that provided a theoretical basis and confirmed the previously observed constancy of $\mathrm{WP}_{\mathrm{b}}$ for a given environment. Since then, only few attempts have been made to combine the scientific advances and the new experimental evidence to improve our understanding of the behavior of $\mathrm{WP}_{\mathrm{b}}$ [e.g., Hsiao (1993) for high $\mathrm{CO}_{2}$; Steduto (1996) and Steduto and Albrizio (2005) for climate normalization procedures]. This is surprising in view of the practical implications that a constant $\mathrm{WP}_{\mathrm{b}}$ would have for the use of a limited amount of water in supplemental irrigation (Oweis et al. 2000) and in regulated deficit irrigation (Fereres et al. 2003), as well 
as in the theoretical approaches to modeling crop production (Steduto 1996).

Actually, the realm of dynamic crop-growth modeling has evolved based on the use of another fundamental and conservative parameter-radiation use efficiency (RUE) - the slope of the relationship between biomass produced and solar radiation intercepted (or absorbed) by the crop canopy. The choice of the RUE formalism (Monteith 1977) was likely influenced by the relative ease by which RUE can be determined as compared to $\mathrm{WP}_{\mathrm{b}}$, and by the fact that the first modeling effort focused on potential yield (de Wit et al. 1970), which is radiation-limited rather than water-limited. Nevertheless, the ever increasing recognition of water as a limiting resource worldwide (Seckler et al. 1998), the knowledge accumulated on crop-water relations and water productivity, and the recent improvements in methods for the determination of $\mathrm{WP}_{\mathrm{b}}$ all argue for more attention be given to the potential offered by $\mathrm{WP}_{\mathrm{b}}$ in crop simulation models. This is supported by the variability encountered in RUE (Sinclair and Muchow 1999; Albrizio and Steduto 2005) along with the better simulation performance in using $\mathrm{WP}_{\mathrm{b}}$ as compared to using RUE observed in a few cases (Steduto and Albrizio 2005).

\section{Theoretical framework and experimental evidence}

In developing the theoretical background and the appropriate framework for analyzing the constancy of $\mathrm{WP}_{\mathrm{b}}$, we follow a stepwise scaling-up approach, from leaf to crop community, in the analysis of the two basic processes involved, water transpiration $(T)$ and net carbon assimilation $(A)$, and its conversion to biomass.

\section{Photosynthetic water productivity—leaf scale}

At the leaf level, we define photosynthetic water productivity $\left(\mathrm{WP}_{\mathrm{p}}\right)$ as the ratio of leaf net carbon dioxide assimilation $\left(A_{1}\right)$ to leaf transpiration $\left(T_{1}\right)$, both expressed as flux rates on a leaf area basis $\left(\mathrm{mol} \mathrm{m}^{-2} \mathrm{~s}^{-1}\right)$. In the gas exchange processes between a leaf and its environment, $\mathrm{CO}_{2}$ and water vapor share the same pathway between the bulk atmosphere and the intercellular air space. While this completes the path for water vapor, $\mathrm{CO}_{2}$ has yet to move in liquid phase from the cell walls to the carboxylating sites of the thylakoids $\left(\mathrm{C}_{3}\right.$ species $)$ or cytosol $\left(\mathrm{C}_{4}\right.$ species $)$. This additional path for $\mathrm{CO}_{2}$ may be ignored when gas exchange is determined under steady state or near steady state conditions. Neglecting the cuticular path and assuming steady state, the corresponding gaseous $A_{1}$ and $T_{1}$ fluxes are expressed as:

$A_{\mathrm{l}}=\frac{\Delta c}{r_{\mathrm{b}}^{\prime}+r_{\mathrm{s}}^{\prime}}=\frac{c_{\mathrm{a}}-c}{r_{\mathrm{b}}^{\prime}+r_{\mathrm{s}}^{\prime}}$

$T_{1}=\frac{\Delta w}{r_{\mathrm{b}}+r_{\mathrm{s}}}=\frac{w_{\mathrm{i}}-w}{r_{\mathrm{b}}+r_{\mathrm{s}}}$

where $\Delta c$ is the difference in $\mathrm{CO}_{2}$ concentration between that of the atmosphere $\left(c_{\mathrm{a}}\right)$ and that in the leaf intercellular air space $\left(c_{\mathrm{i}}\right) ; \Delta w$ is the water vapor concentration difference between the leaf intercellular air space $\left(w_{\mathrm{i}}\right)$ and the atmosphere $\left(w_{\mathrm{a}}\right) ; r_{\mathrm{b}}^{\prime}$ and $r_{\mathrm{S}}^{\prime}$ are the boundary layer and stomatal resistances, respectively, for $\mathrm{CO}_{2}$ transport; and $r_{\mathrm{b}}$ and $r_{\mathrm{s}}$ are the boundary layer and stomatal resistances, respectively, for water vapor transport.

Equations 1 and 2 express the $A$ and $T$ fluxes in purely physical terms while all the complex metabolic processes of $\mathrm{CO}_{2}$ fixation at the biochemical level are imbedded in the $c_{\mathrm{i}}$ term of $\Delta c$.

Along the path described, both gases encounter the same resistance to diffusion except for their different binary diffusivity due to a difference in molecular mass (von Caemmerer and Farquhar 1981). The relationship between the total resistance to water vapor transport $\left(r=r_{\mathrm{b}}+r_{\mathrm{s}}\right)$ and the total resistance to $\mathrm{CO}_{2}$ transport $\left(r^{\prime}=r_{\mathrm{b}}^{\prime}+r_{\mathrm{s}}^{\prime}\right)$ is about constant under high turbulence (a condition typical of gas-exchange measurements in cuvettes, and very common in open fields). Farquhar and Sharkey (1982) determined that $r \cong 0.625 r^{\prime}$. This constant relationship indicates that any change of the resistance to gas transport will have a similar impact on $A_{1}$ and $T_{1}$.

Under steady-state conditions then, photosynthetic water productivity of single leaves is expressed as:

$\mathrm{WP}_{\mathrm{p}}=\frac{A_{1}}{T_{1}}=\frac{\left(r_{\mathrm{b}}+r_{\mathrm{s}}\right)}{\left(r_{\mathrm{b}}^{\prime}+r_{\mathrm{s}}^{\prime}\right)} \frac{\Delta c}{\Delta w}=\frac{r}{r^{\prime}} \frac{\Delta c}{\Delta w} \cong 0.625 \frac{\Delta c}{\Delta w}$

Equation 3 underlines the dependence of $\mathrm{WP}_{\mathrm{p}}$ on the concentration difference or gradient of the two gases. At any given $\Delta w$, an increase in $\Delta c$ under elevated atmospheric $\mathrm{CO}_{2}$ will increase $\mathrm{WP}_{\mathrm{p}}$. Similarly, $\mathrm{WP}_{\mathrm{p}}$ is influenced by the evaporative demand of the atmosphere through $\Delta w$ and will vary in different climates unless it is normalized for $\Delta w$. At the leaf scale, this normalization is quite simple, as $\Delta w$ is determined during the flux measurements of gas-exchange.

To normalize $\mathrm{WP}_{\mathrm{p}}$ for $\Delta w$, both sides of Eq. 3 are multiplied by $\Delta w$. That will cancel the denominator of Eq. 3 and make the normalized $\mathrm{WP}_{\mathrm{p}}$ dependent only on $\Delta c$. Also, if $c_{\mathrm{a}}$ is maintained constant by the 
gas-exchange system, the normalized $\mathrm{WP}_{\mathrm{p}}\left(\mathrm{WP}_{\mathrm{p}}^{*}\right)$ will only be influenced by the degree of variation in $c_{\mathrm{i}}$.

Normalizing for $\Delta w$ and rearranging,

$$
\begin{aligned}
\mathrm{WP}_{\mathrm{p}}^{*} & =0.625 \frac{\Delta c}{\Delta w} \Delta w=0.625\left(c_{\mathrm{a}}-c_{\mathrm{i}}\right) \\
& =0.625 c_{\mathrm{a}}-0.625 c_{\mathrm{i}}=k-0.625 c_{\mathrm{i}}
\end{aligned}
$$

where $k=0.625 c_{\mathrm{a}}$. Equation 4 shows that for a given $c_{\mathrm{a}}, \mathrm{WP}_{\mathrm{p}}^{*}$ is a linear function of $c_{\mathrm{i}}$ with an intercept of $k\left(=0.625 c_{\mathrm{a}}\right)$ and a slope of 0.625 . That is, under a given $c_{\mathrm{a}}$ and evaporative demand, $\mathrm{WP}_{\mathrm{p}}$ is critically dependent on $c_{\mathrm{i}}$.

As depicted in Fig. 1, $c_{\mathrm{i}}$ represents a balance between the importation of $\mathrm{CO}_{2}$ into the intercellular space through stomata and air boundary layer, and the depletion or utilization of the intercellular $\mathrm{CO}_{2}$ by photosynthetic carboxylation. The rate of importation is jointly determined by the level of $c_{\mathrm{a}}$ relative to $c_{\mathrm{i}}$ $(\Delta c)$ and the relevant resistances $\left(r_{\mathrm{b}}^{\prime}\right.$ and $\left.r_{\mathrm{s}}^{\prime}\right)$ in the gaseous transport pathway. The rate of depletion is jointly determined by the level of $c_{\mathrm{i}}$, the activities of the enzymes controlling the $\mathrm{CO}_{2}$ dissolution and fixation processes in photosynthesis, and the level of the substrates as $\mathrm{CO}_{2}$ acceptors. The lumped resistance $r_{\mathrm{m}}^{\prime}$ in the figure represents essentially the overall biochemical resistance to $\mathrm{CO}_{2}$ fixation. Plants have apparently evolved feedback and feedforward mechanisms (dashed lines) to keep the importation and depletion of $\mathrm{CO}_{2}$ in balance most of the time so that $c_{\mathrm{i}}$ is conservative. This implies that photosynthetic capacity and stomatal opening are coordinated and operate in concert in the leaf. Under fast changing conditions, however, $c_{\mathrm{i}}$ does fluctuate but then gradually returns close to its set value. This suggests that when one of the two opposing processes, either the importation or depletion of $\mathrm{CO}_{2}$, is perturbed, the

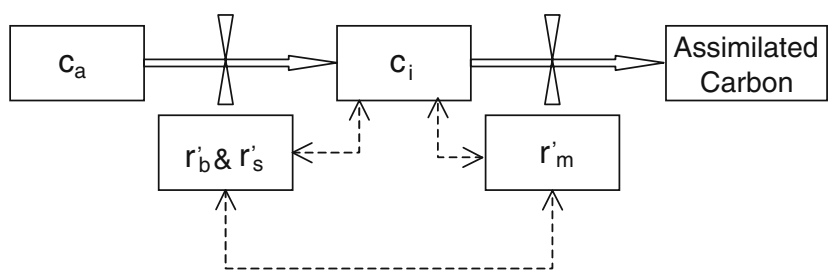

Fig. 1 Schematic view of leaf intercellular $\mathrm{CO}_{2}$ concentration $\left(c_{\mathrm{i}}\right)$ as a balance between the importation and depletion of $\mathrm{CO}_{2}$. Importation of ambient $\mathrm{CO}_{2}\left(c_{\mathrm{a}}\right)$ is regulated by boundary layer $\left(r_{\mathrm{b}}^{\prime}\right)$ and stomatal $\left(r_{\mathrm{s}}^{\prime}\right)$ resistances, and depletion of $\mathrm{CO}_{2}$ by carbon assimilation is dependent on the biochemistry of photosynthesis $\left(r_{\mathrm{m}}^{\prime}\right)$. Control loops (feedback and feed forward), indicated by the dashed lines, appear to have evolved to optimize the gas exchange processes, resulting in a conservative $c_{\mathrm{i}}$ other adjusts with some lag to keep the system in balance and $c_{\mathrm{i}}$ nearly constant.

There has been substantial experimental evidence showing that for many species, $c_{\mathrm{i}}$ tends to remain constant under a range of conditions (Wong et al. 1979; Pearcy 1983; review by Morrison 1987; Hsiao and Jackson 1999) including water stress when the stress develops gradually, as it generally occurs in the field. It is also well known that there is a difference in $c_{\mathrm{i}}$ between the leaves of $\mathrm{C}_{3}$ and $\mathrm{C}_{4}$ species, due to differences in their photosynthetic pathways (Osmond et al. 1982). Near constancy of $c_{\mathrm{i}}$ has been observed with variations in temperature (e.g., Björkman 1981), radiation (e.g., Bolaños and Hsiao 1991), water supply (e.g., Wong et al. 1979; Hirasawa et al. 1995), leaf nitrogen content (e.g., Wong et al. 1979) and salinity stress (Steduto et al. 2000). For species with stomatal response to humidity, however, as water vapor gradient from the leaf interior to the air $(\Delta w)$ increases stomata react by narrowing and $c_{\mathrm{i}}$ decreases (Morison 1987). Such responses were apparently influenced by changes in leaf temperature and plant water status (e.g., Steduto et al. 1997) and will be discussed further in "Some unresolved issues".

The ample evidence under most circumstances on the tendency of $c_{\mathrm{i}}$ to remain constant at a constant $c_{\mathrm{a}}$, i.e., a constant $c_{\mathrm{i}} / c_{\mathrm{a}}$ ratio, is an indication that stomata behave at the leaf scale in a manner that leads to a constant $\mathrm{WP}_{\mathrm{p}}^{*}$.

By considering the ratio $c_{\mathrm{i}} / c_{\mathrm{a}}=\alpha$ as constant, $c_{\mathrm{i}}=$ $\alpha c_{\mathrm{a}}$, and Eq. 4 can be arranged as follows

$\mathrm{WP}_{\mathrm{p}}^{*}=0.625 c_{\mathrm{a}}-0.625 c_{\mathrm{i}}=0.625(1-\alpha) c_{\mathrm{a}}=k^{*} c_{\mathrm{a}}$

clearly indicating that $\mathrm{WP}_{\mathrm{p}}^{*}$ is proportional to the increase in ambient $\mathrm{CO}_{2}$ by the proportionality of $k^{*}$, as long as $\alpha$ stays constant. Using the widely accepted generalized values for $\alpha$ of 0.7 and 0.4 for $C_{3}$ and $C_{4}$ species, respectively (Morison 1987; Wong et al. 1979), $k^{*}$ and $\mathrm{WP}_{\mathrm{p}}^{*}$ take on the following values:

$$
\begin{aligned}
k^{*} & =0.1875 \quad \mathrm{WP}_{\mathrm{p}}^{*}=0.1875 c_{\mathrm{a}} \text { for } C_{3} \\
\text { and } \quad k^{*} & =0.375 \quad \mathrm{WP}_{\mathrm{p}}^{*}=0.375 c_{\mathrm{a}} \quad \text { for } \mathrm{C}_{4} .
\end{aligned}
$$

$k^{*}$ is unitless and the units for $\mathrm{WP}_{\mathrm{p}}^{*}$ are the same as that for $c_{\mathrm{a}}$ and $c_{\mathrm{i}}$.

Figure 2 presents a comparison of three sets of $\mathrm{WP}_{\mathrm{p}}^{*}$ values spanning a range of $c_{\mathrm{a}}$ for several field grown crops. One set was experimentally determined; one set was calculated with Eq. 4 using the experimentally measured $c_{\mathrm{i}}$ that corresponded to the experimental $c_{\mathrm{a}}$ 
Fig. 2 Examples of leaf photosynthetic water productivity $\left(\mathrm{WP}_{\mathrm{p}}^{*}\right)$, normalized for $\Delta w$, as dependent on ambient $\mathrm{CO}_{2}$ concentration $\left(c_{\mathrm{a}}\right)$, for different crops under well watered and high nitrogen (left plots) and water deficient and low nitrogen (right plots) conditions. Measurements (dotted line with filled circles) were obtained from the determination under steady state conditions of $A_{l}$ versus $\mathrm{CO}_{2}$ response curves, using a portable leaf-photosynthesis open-system (Li-6400, LiCor, Lincoln, NE, USA) following the procedure described in Steduto et al. (2000). Dashed line (with open circles) and continuous lines (with no symbol) represents values calculated according to Eqs. 4 and 5, respectively. Data from P. Steduto and R. Albrizio (unpublished)

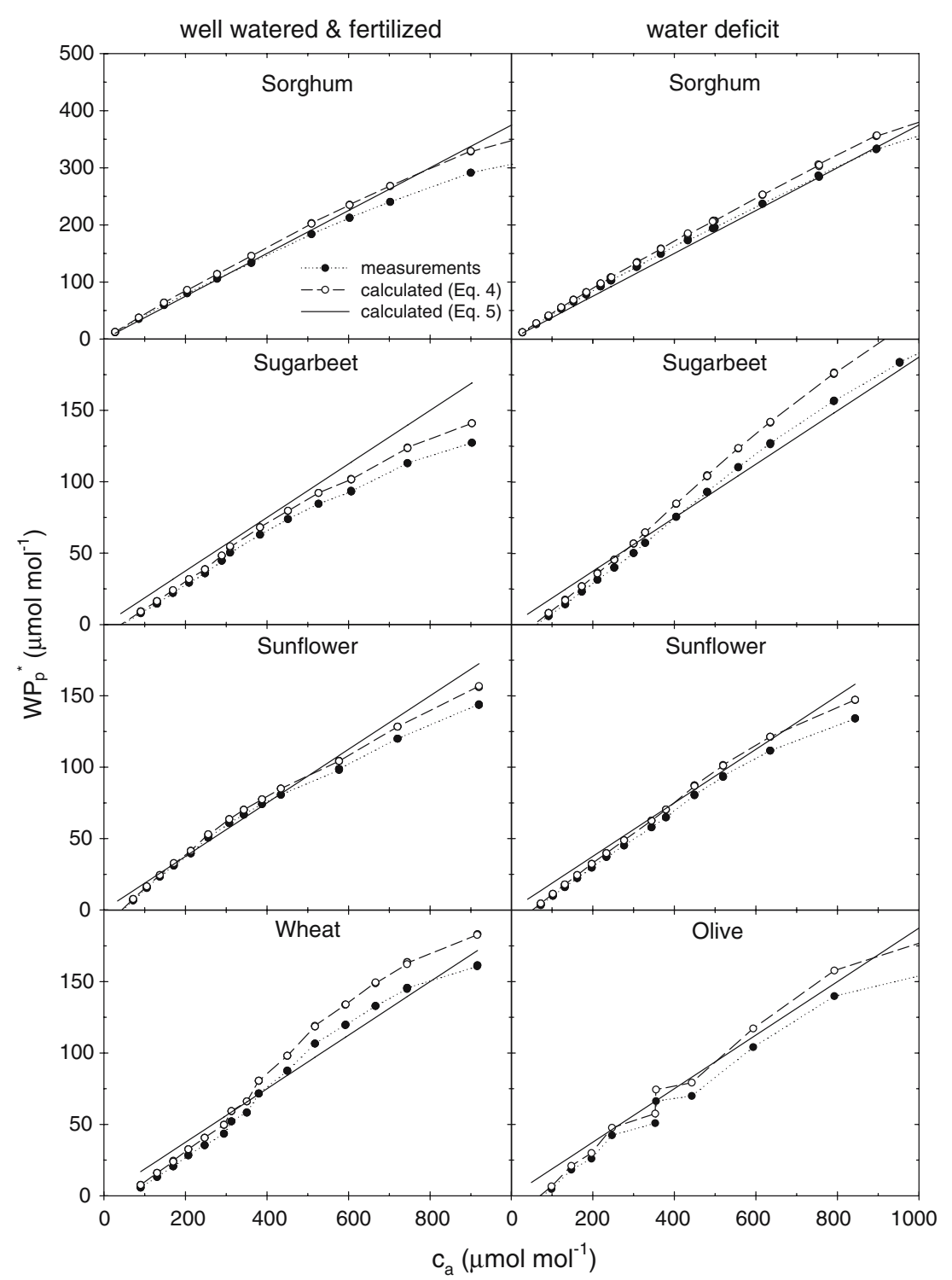

values (plotted), and another was calculated from $c_{\mathrm{a}}$ using Eq. 5. The general agreement found among the three sets of $\mathrm{WP}_{\mathrm{p}}^{*}$ for these crops, particularly over the range of $c_{\mathrm{a}}$ that is not excessively high, confirms the validity of the assumptions made to arrive at the simple expressions defining normalized photosynthetic water productivity at the leaf scale $\left(\mathrm{WP}_{\mathrm{p}}^{*}\right)$. Most notable is the fact that Eq. 5 makes no differentiation among crop species except between $\mathrm{C}_{3}$ and $\mathrm{C}_{4}$ and there is no parameter to adjust regardless of the crop, and no experimental measurement to make as long as $c_{\mathrm{a}}$ is known. Yet the equation yielded $\mathrm{WP}_{\mathrm{p}}^{*}$ matching closely the measured values for the $\mathrm{C}_{3}$ species wheat, sunflower, sugar beet and olive, and the $\mathrm{C}_{4}$ species sorghum, over a wide range of $c_{\mathrm{a}}$. It should be mentioned though, that the measured and the simulated responses tend to diverge at high $c_{\mathrm{a}}$. This is most likely because the capacity of leaves to maintain $c_{\mathrm{i}}$ constant diminishes as $\mathrm{CO}_{2}$ saturation is approached, as may be expected when $c_{\mathrm{a}}$ was changed quickly in these shortterm experiments, with little opportunity for acclimation by the leaves.

Once again, it bears emphasis that only $c_{\mathrm{a}}$ needs to be known in order to use Eq. 5, and no other measurements are required.

The emphasis here is on the constancy of the ratio of $c_{\mathrm{i}}$ to $c_{\mathrm{a}}(\alpha)$ and the constancy of $c_{\mathrm{i}}$ at a given $c_{\mathrm{a}}$. Nonetheless, following the discovery of the variation in carbon isotope discrimination and its relation to WP (Farquhar and Richards 1984; Farquhar et al. 1989), efforts have been made to breed $C_{3}$ crops for higher WP by selecting for reduced carbon isotope 


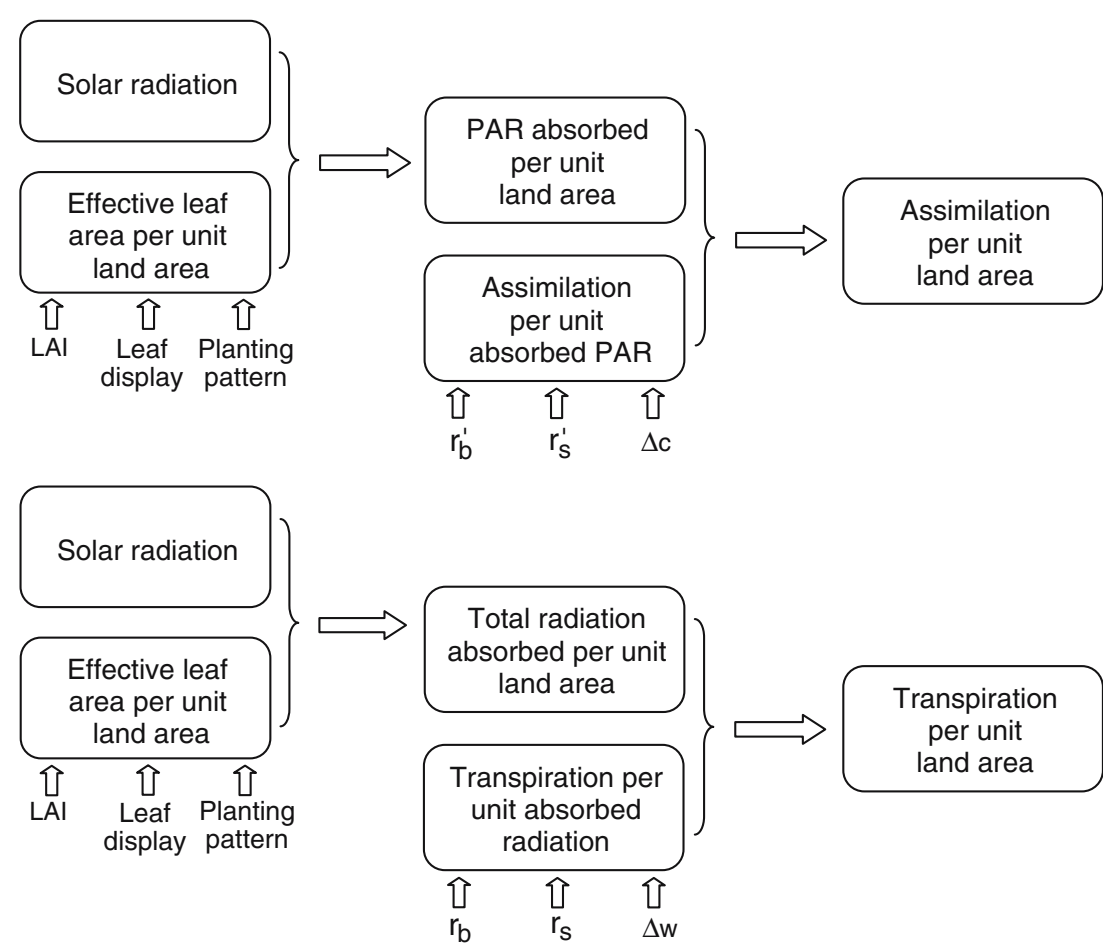

Fig. 3 Similarities and differences in factors affecting assimilation and transpiration of canopies. Arrows indicate causal relations. All considerations are on a basis of land area. Symbols are: $r_{\mathrm{b}}^{\prime}$, boundary layer resistance to $\mathrm{CO}_{2} ; r_{\mathrm{s}}^{\prime}$, stomatal resistance to $\mathrm{CO}_{2} ; r_{\mathrm{b}}$, boundary layer resistance to water vapor; $r_{\mathrm{s}}$, stomatal resistance to water vapor; $\Delta c$, difference in $\mathrm{CO}_{2}$ concentration between the atmosphere and the leaf intercellular space; and $\Delta w$, difference in water vapor concentration between leaf intercellular space and the atmosphere. Note that because resistances to

discrimination, which corresponds to a lower $\alpha$. Obviously genetic variation in $\alpha$ exists. The key question is how much can we expect $\alpha$ to vary in the coming few decades for widely used crop cultivars. So far the variations appear to be small for most of the crop species examined, as discussed further in "Some unresolved issues".

\section{Photosynthetic water productivity—canopy scale}

In an agricultural system, assimilation and transpiration by the crop canopy determine the fluxes of $\mathrm{CO}_{2}$ and water vapor and thus, canopy photosynthetic water productivity $\left(\mathrm{WP}_{\mathrm{p}}^{\mathrm{c}}\right)$, and ultimately, biomass water productivity $\left(\mathrm{WP}_{\mathrm{b}}\right)$. As we scale up from leaf to canopy, there are additional features that must be taken into account because the consideration is now on a land area basis instead of leaf area basis. When the coverage of the land by crop canopy is incomplete, the capture of radiation becomes critical for both photosynthesis and water loss.
$\mathrm{CO}_{2}$ and to water vapor are proportional to each other, most of the factors affecting assimilation have analogous impact on transpiration. One clear difference is the driving force for gas transport, with $\Delta c$ for assimilation and $\Delta w$ for transpiration. See text for possible differences caused by PAR being only a portion of the total radiation, and sensible heat flux providing another way to exchange energy. Modified from Hsiao and Bradford (1983) and Hsiao (1993)

The commonality and differences in the factors that affect canopy photosynthesis and canopy transpiration are summarized in Fig. 3. The extent of radiation capture by a crop depends on the amount of leaf area, normally evaluated by the leaf area index (LAI), on the geometric arrangement of the leaves within the canopy, as well as on the angle and intensity of incident radiation. Therefore, in addition to solar radiation, plant factors, particularly plant density and the stage of vegetative growth, are critical determinants of radiation interception when the canopy is incomplete. As in leaves, the process of canopy transpiration $\left(T_{\mathrm{c}}\right)$ shares the same source of captured energy as the canopy assimilation $\left(A_{\mathrm{c}}\right)$. Of the total captured solar radiation though, only the fraction that is photosynthetically active (PAR) is effective in $\mathrm{CO}_{2}$ assimilation, while the whole spectrum is used for transpiration. PAR, however, is a fairly constant fraction of the incident solar radiation (Meek et al. 1984; Varlet-Grancher et al. 1989 ) as is the ratio of absorptance of PAR to nonPAR radiation for the leaves of many species (Stanhill 
1981). Another fact to recognize is that at the canopy level, $A_{\mathrm{c}}$ of many crops usually does not reach light saturation but has an essentially linear response to irradiance (Biscoe et al. 1975; Louwerse 1980; Asseng and Hsiao 2000). Consequently, any change in the amount of radiation captured by the canopy (e.g., difference in effective leaf surface area, weather, etc.) would affect in a similar way $A_{\mathrm{c}}$ and $T_{\mathrm{c}}$. Thus, at the canopy level, not only the $\mathrm{CO}_{2}$ and water vapor share much of the transport pathway, they also share the dominant energy source. There is, however, a difference in that sensible heat flux can either add or remove energy for transpiration from the canopy independent of radiation. Overall though, the sharing of radiative energy source is a critical and often even dominant factor in linking assimilation and transpiration rates at the canopy level.

Figure 3 also emphasizes the most obvious difference between the assimilation and transpiration processes, namely, the difference in driving force for gas transport, being $\Delta c$ for $\mathrm{CO}_{2}$, and $\Delta w$ for water vapor, two virtually independent variables. This provides some means to improve $\mathrm{WP}_{\mathrm{p}}^{\mathrm{c}}$, through the manipulation of either or both of these parameters. Equally important, for $\mathrm{WP}_{\mathrm{p}}^{\mathrm{c}}$ to be conservative in different environments, it must be normalized for $\Delta c$ and $\Delta w$.

Data on canopy assimilation and transpiration, measured simultaneously to determine $\mathrm{WP}_{\mathrm{p}}^{\mathrm{c}}$ over many days, are not extensive. Figure 4 presents some results for sorghum, wheat, and chickpea obtained in the field. The constancy of $\mathrm{WP}_{\mathrm{p}}^{\mathrm{c}}$ is obvious from the straight line relationship between $\Sigma A_{\mathrm{c}}$ and $\Sigma T_{\mathrm{c}}$. It is necessary to

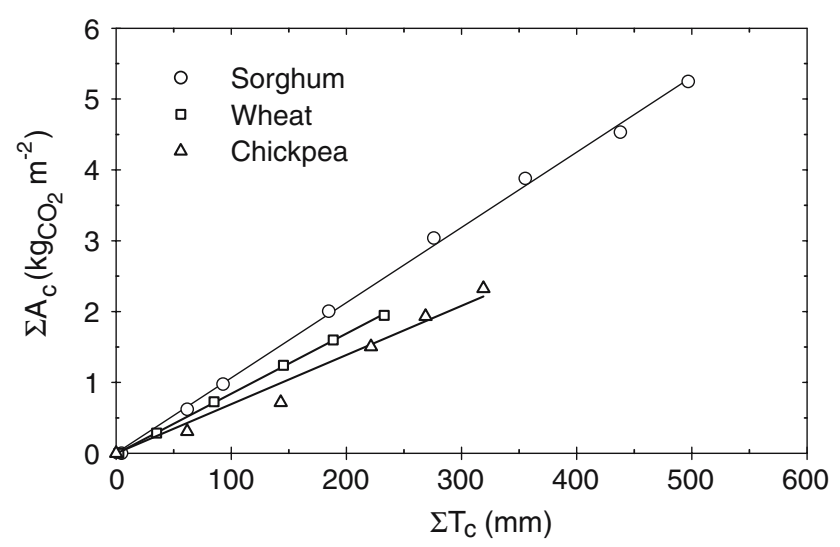

Fig. 4 Relationships between cumulative daytime canopy net assimilation $\left(A_{\mathrm{c}}\right)$ and cumulative daytime canopy transpiration $\left(T_{\mathrm{c}}\right)$ for sorghum, wheat and chickpea. The slope of the relationships represents $W_{\mathrm{p}}^{\mathrm{c}}$. Measurements were taken when the crops were all at full canopy cover, and soil evaporation was assumed to be negligible (redrawn from Steduto and Albrizio 2005) point out, however, that the ratio $A_{\mathrm{c}} / T_{\mathrm{c}}$ actually varies substantially over diurnal cycles (Xu and Hsiao 2004), mostly because evaporative demand of the atmosphere varies diurnally. These variations apparently average out when data were accumulated over periods of many days, as is the case for the data in Fig. 4.

The data in Fig. 4 are for day time only. As the temporal scale increases from instantaneous measurements of $A_{\mathrm{c}}$ to periods up to a season, more factors must be taken into account. Leaves are not the only components of the canopy. Structural and reproductive organs grow and develop during the crop cycle, changing dimensions, composition, and respiratory requirements as the season progresses. Almost all of the seasonal data in the literature are for biomass water productivity $\left(\mathrm{WP}_{\mathrm{b}}\right)$. Data on seasonal photosynthetic water productivity $\left(\mathrm{WP}_{\mathrm{p}}^{\mathrm{c}}\right)$ are rare because continuous measurement of $A_{\mathrm{c}}$ and $\mathrm{WP}_{\mathrm{p}}^{\mathrm{c}}$ over a season is extremely difficult to obtain. Changing from $A_{\mathrm{c}}$ to biomass requires an analysis of the respiratory costs in relation to $A_{\mathrm{c}}$, and of the chemical composition and carbon requirements of the biomass.

Converting the assimilated $\mathrm{CO}_{2}$ into the products used for growth, maintenance, transport and assimilation of mineral nutrients requires energy supplied by respiration. It is customary to separate respiration into two components, that used in growth and that used in the other processes (so called maintenance). The total respiration of a canopy $\left(R_{\mathrm{c}}\right)$ could consume from one fourth to two thirds of the total assimilates over a plant's life cycle (Amthor 1989) and may affect $A_{\mathrm{c}}$ variably over the season. As $A_{\mathrm{c}}$ is the measured net assimilation, variation in $R_{\mathrm{c}}$ with crop ontogeny may affect measure of $A_{\mathrm{c}}$ over the season. The other important consideration is the composition of the biomass. Not only does the biomass composition determine the respiratory growth requirements (Penning de Vries et al. 1974) but also the maintenance costs (Amthor 1989).

All this implies that overall, a linear relationship between $A_{\mathrm{c}}$ and $T_{\mathrm{c}}$, i.e., a constant $\mathrm{WP}_{\mathrm{p}}^{\mathrm{c}}$ (e.g., as in Fig. 4) would be expected only if the relationship between $R_{\mathrm{c}}$ and $A_{\mathrm{c}}$ is also linear (Charles-Edwards 1982). Fortunately, more and more evidence is appearing indicating an approximate fixed ratio of assimilation to respiration for a given species or genotype (Amthor 1995). This seems to be the case even as environmental conditions vary, including that in temperature (Gifford 1995), $\mathrm{CO}_{2}$ concentration (Cheng et al. 2000), and nitrogen availability within a reasonable range (Garcia et al. 1988).

The tight correlations between cumulative $A_{\mathrm{c}}$ and $R_{\mathrm{c}}$ along the season for sunflower, sorghum, wheat, and 
Fig. 5 Relationship between cumulative daytime canopy net assimilation $\left(A_{\mathrm{c}}\right)$ and cumulative nighttime canopy dark respiration $\left(R_{\mathrm{c}}\right)$ for $\mathbf{a}$ sunflower, b sorghum and c wheat and chickpea. Slopes of the post anthesis regression lines for $N_{0}$ and $N_{1}$ are not significantly different at $5 \%$ probability (from Albrizio and Steduto 2003)
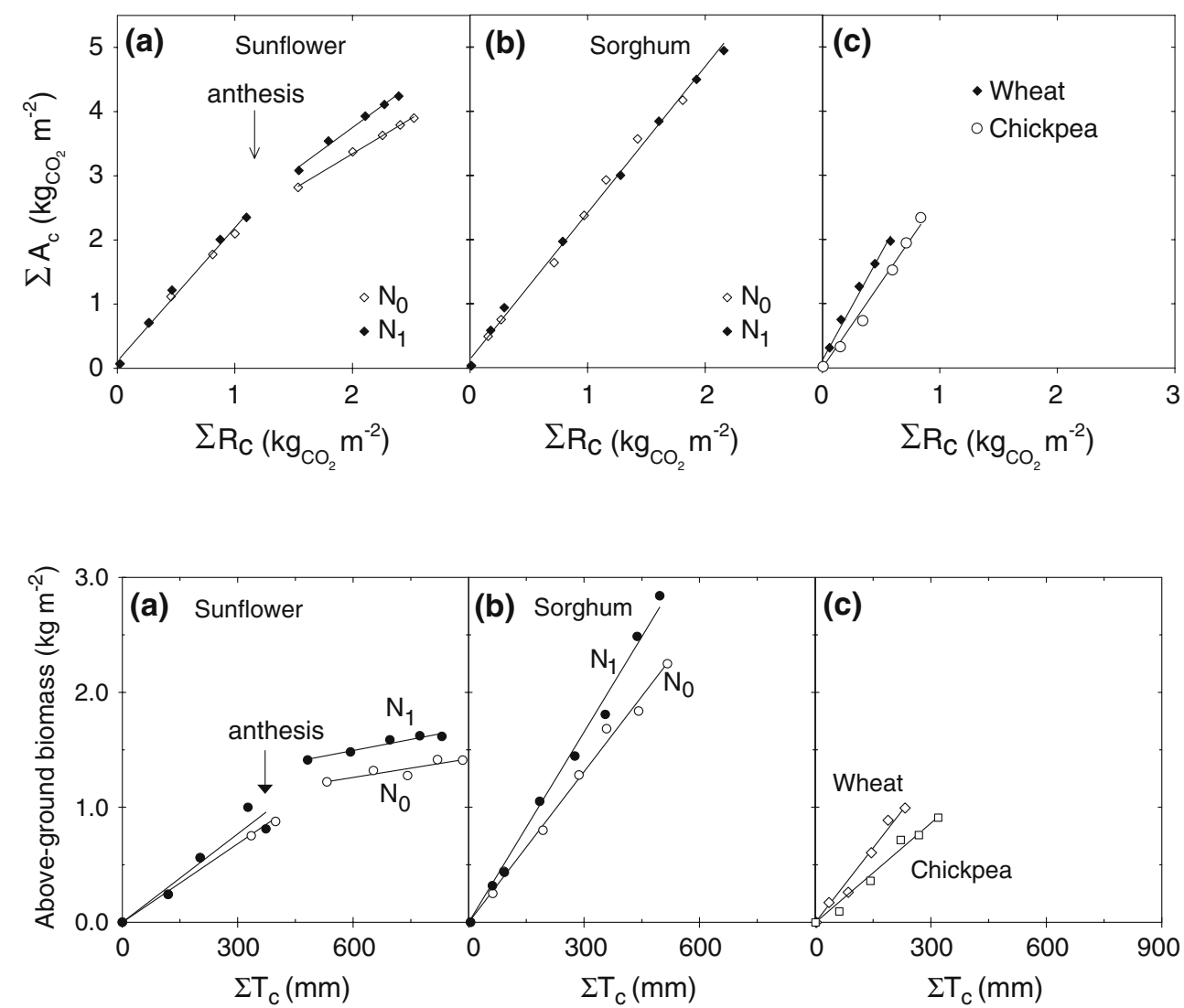

Fig. 6 Relationship between cumulative biomass and cumulative canopy transpiration $\left(T_{\mathrm{c}}\right)$ for a sunflower, b sorghum and c wheat and chickpea (from Steduto and Albrizio 2005). Sunflower and sorghum data were obtained under two levels of nitrogen nutrition. The differences in the slope of the plot between the two levels of nitrogen is statistically significant only for sorghum chickpea are illustrated in Fig. 5. The change in the slope of the linear relationship for sunflower after anthesis in Fig. 5a is the consequence of a significant increase in respiratory requirements due to oil production in the seeds (Whitfield et al. 1989). The increase in $\mathrm{CO}_{2}$ release through respiration then leads to a lower net canopy assimilation and lower ratio of $A_{\mathrm{c}}$ to $R_{\mathrm{c}}$. The fact that two different levels of nitrogen yielded the same relationship between $A_{\mathrm{c}}$ and $R_{\mathrm{c}}$ for a $\mathrm{C}_{3}$ as well as a $\mathrm{C}_{4}$ species is illustrated by the data for pre-anthesis sunflower (Fig. 5a) and for sorghum (Fig. 5b). These results support the concept of fairly constant carbon use efficiency throughout the crop life cycle, provided that the composition of biomass does not change significantly (as in Fig. 5a). Research on woody plants and forest trees has led to the use of a constant ratio between gross and net primary production in the accurate simulation of the growth of tree stands of many species (Landsberg et al. 2003).

The data in Fig. 4 demonstrated clearly the constancy of photosynthetic water productivity at the canopy scale $\left(\mathrm{WP}_{\mathrm{p}}^{\mathrm{c}}\right)$. This is supported and consistent with the underlying factors discussed so far: (a) the conservative behavior of leaf $\mathrm{WP}_{\mathrm{p}}$; (b) the role of solar radiation intercepted by the canopy in determining both $A_{\mathrm{c}}$ and $T_{\mathrm{c}}$; and (c) the conservative behavior of canopy carbon use efficiency (Fig. 5) provided that chemical composition of the biomass does not change.

From net carbon gain to biomass

The next step is to scale up from daily net $A_{\mathrm{c}}$ to seasonal biomass, in which the only new process influencing biomass accumulation would be the metabolic costs for the construction and maintenance of the biomass. Given that the composition of vegetative parts of many crop species is very similar (Penning de Vries et al. 1983) and does not change substantially, biomass should also be linearly related to transpiration, but the slope of biomass versus transpiration plot $\left(\mathrm{WP}_{\mathrm{b}}\right)$ will be lower compared to the corresponding plot for $\mathrm{WP}_{\mathrm{p}}^{\mathrm{c}}$. This is clearly evident with data obtained in the same set of experiments and depicted in Fig. 6. Again, in the case of sunflower (Fig. 6a) the slope during the reproductive phase is less than that in the vegetative phase. Similar behavior should be expected in those crops where the reproductive organ has high protein and/or oil content, such as soybean, peanut (Angus et al. 1983), sunflower, etc. Penning de Vries et al. (1983) provide an assessment of the metabolic 
costs of production of the harvestable organs for most crops from where it is possible to infer the trend in $\mathrm{WP}_{\mathrm{b}}$ depending on the nature of the yield product.

Although the analyses and data above have addressed situations where only above-ground biomass is considered, constant $\mathrm{WP}_{\mathrm{b}}$ has been described for root and tuber crops such as sugar beet (e.g., Clover et al. 2001), and potato (e.g., Tanner 1981). Presumably, the constancy in water productivity of both above-ground biomass and root biomass in the case of root crops is a consequence of a homeostatic growth response of root and shoot (Brouwer 1983), as earlier indicated. There is, however, a shift under water or nutrient deficiencies in the ratio in favor of the root. But, as already mentioned, this shift has relatively minor impact on crop $\mathrm{WP}_{\mathrm{b}}$ because shoot biomass dominates in cases of crops harvested for shoots, and root biomass dominates in cases of crops grown for roots.

\section{Normalization of biomass water productivity for climate}

The virtually constant $\mathrm{WP}_{\mathrm{p}}^{\mathrm{c}}$ and $\mathrm{WP}_{\mathrm{b}}^{\mathrm{c}}$ in Figs. 4 and 6 , respectively, were for the cases where environmental conditions did not vary markedly over periods of weeks to months. By analogy with the leaf $\mathrm{WP}_{\mathrm{p}}$, however, one expects $\mathrm{WP}_{\mathrm{p}}^{\mathrm{c}}$ and $\mathrm{WP}_{\mathrm{b}}^{\mathrm{c}}$ to still be dependent on the magnitudes of the driving forces for water vapor and $\mathrm{CO}_{2}$ transport, which are determined by the environment. Thus, there is a need to normalize $\mathrm{WP}_{\mathrm{p}}$ and $\mathrm{WP}_{\mathrm{b}}$ for the climate, specifically, for evaporative demand of the atmosphere to extrapolate water productivity values between climatic zones, and for atmospheric $\mathrm{CO}_{2}$ concentration to extrapolate between atmospheric $\mathrm{CO}_{2}$ status. The latter is necessary to evaluate and make use of old data (e.g., those analyzed by de Wit 1958) and to accommodate future rise in atmospheric $\mathrm{CO}_{2}$.

Normalization for atmospheric evaporative demand

The conceptual normalization of $\mathrm{WP}_{\mathrm{b}}$ for the evaporative demand of the atmosphere can take two routes (Tanner and Sinclair 1983; Steduto and Albrizio 2005):

(1) normalizing via the "transpiration gradient", or (2) normalizing via "reference transpiration flux".

The gradient-normalizing route is derived from the leaf-scale gas transport model (Eqs. 1, 2). For the canopy, the flux-gradient theory (Norman 1979) is applied considering the canopy as a "big leaf" (Lhomme 1991), with the latent heat flux $(\lambda E)$ expressed as $\lambda E=\frac{\rho_{\mathrm{a}} c_{\mathrm{p}} g_{\mathrm{w}}}{\gamma} \Delta e$

where $\lambda$ is the specific latent heat of vaporization $\left(\mathrm{J} \mathrm{kg}^{-1}\right)$; $E$ is the evaporation or water vapor flux $\left(\mathrm{kg} \mathrm{m}^{-2} \mathrm{~s}^{-1}\right)$, all due to transpiration; $\rho_{\mathrm{a}}$ is the air density $\left(\mathrm{kg} \mathrm{m}^{-3}\right) ; c_{\mathrm{p}}$ is the specific heat capacity of the air $\left(\mathrm{J} \mathrm{kg}^{-1}{ }^{\circ} \mathrm{C}\right) ; g_{\mathrm{w}}$ is the total conductance for water vapor transport $\left(\mathrm{m} \mathrm{s}^{-1}\right)$, including both aerodynamic and canopy conductances; $\gamma$ is the psychrometric constant $\left(\mathrm{kPa}^{\circ} \mathrm{C}^{-1}\right)$; and $\Delta e$ is the leaf-to-air vapor pressure difference $(\mathrm{kPa})$.

Following the derivation of Tanner and Sinclair (1983) at the canopy level, $\mathrm{WP}_{\mathrm{p}}^{\mathrm{c}}$ and $\mathrm{WP}_{\mathrm{b}}$ can be normalized for the leaf-to-air water vapor pressure difference $(\Delta e)$, representing the driving force of the transpiration process (analogous to $\Delta w$ in Eq. 2), through the following equations

$\mathrm{WP}_{\mathrm{p}}^{\mathrm{c}, *}=\frac{\sum_{i=1}^{n} A_{\mathrm{c}, i}}{\sum_{i=1}^{n} t_{\mathrm{i}}\left(\frac{T}{\Delta e}\right)_{i}}$

$\mathrm{WP}_{\mathrm{b}}^{*}=\frac{\text { Biomass }}{\sum_{i=1}^{n} t_{\mathrm{i}}\left(\frac{T_{\mathrm{c}}}{\Delta e}\right)_{\mathrm{i}}}$

The summations are over a total of $n$ number of time intervals of the same length with $i$ as the running number designating each interval. The length of the interval (in days) is represented by $t$. Biomass denotes the gain in biomass from the beginning to the end of the summation period. In contrast, $A_{\mathrm{c}}, T_{\mathrm{c}}$ and $\Delta e$ denote the quantity cumulated during each interval $i$. Ideally, Eqs. 7 and 8 should be applied to the daily data $\left(t_{\mathrm{i}}=1\right.$ day $)$ to normalize. Not many studies provide sequential daily data, however, as the majority of the studies employed time intervals of at least 1 week $\left(t_{i}=\right.$ 7 days) or longer in the measurements of $T_{\mathrm{c}}$. Also, with respect to $\mathrm{WP}_{\mathrm{p}}, t_{\mathrm{i}}$ often varies from interval to interval (e.g., $t_{\mathrm{i}}=7$ days, $t_{2}=5$ days, $t_{3}=10$ days, etc.). For practical purposes, Eq. 8 is usually used in an alternative form, namely:

$\mathrm{WP}_{\mathrm{b}}^{*}=\frac{\text { Biomass }}{\sum_{i=1}^{n}\left(\frac{T_{\mathrm{c}}}{\overline{\Delta e}}\right)_{i}}$

where $\overline{\Delta e}$ is the mean daily $\Delta e$ for time interval $i$. Therefore, when the interval duration varies from one to another (i.e., $t_{\mathrm{i}}$ not constant), Eq. 9 must be used.

At the canopy scale, $\Delta e$ depends on air vapor pressure and temperature of the canopy surface because leaf (actually leaf interior) vapor pressure is a function of leaf temperature. However, since canopy temperature is not generally available, the practical normalization of 
$\mathrm{WP}_{\mathrm{p}}^{\mathrm{c}}$ and $\mathrm{WP}_{\mathrm{b}}$ for evaporative demand (Tanner and Sinclair 1983) is usually approximated by replacing $\Delta e$ with the atmospheric vapor pressure saturation deficit (VPD, using same units), implicitly assuming that air and canopy temperatures are the same.

This approximation has important drawbacks. For one, $\Delta e$ could be substantially lower than VPD when canopy temperature is cooler than air temperature under high transpiration flux or positive advection of sensible heat, and $\Delta e$ could be substantially higher than VPD when canopy temperature is hotter than air temperature due to water stress or negative advection of sensible heat (Paw U and Gao 1988; Asseng and Hsiao 2000). Furthermore, the normalization becomes very sensitive to low VPD values, giving unreliable results in such conditions (Stockle et al. 2003). In addition to the inaccuracy of the approximation under advective conditions, normalization by VPD encounters a more practical problem-a strong dependence of the calculated value of VPD on the type of weather data available and the method selected for calculation (Allen et al. 1998). Thus, the normalized WP may be substantially different unless the same kind of weather data (whether hourly, daily mean from hourly, daily based on maximum and minimum, etc.) and the same method of calculation are used.

Penman (1948), in his derivation of the latent heat flux equation named after him, found a better solution by approximating the canopy temperature with air temperature and the approximate slope of saturated vapor pressure versus temperature, and then combining the sensible heat flux equation and the energy balance equation. The solution given by Penman (1948) is the well known latent-heat flux equation that combines the "energy" and the "aerodynamic" components of the latent heat flux and that was further extended by Monteith (1980) to incorporate the aerodynamic and canopy components through conductance parameters. The fully developed Penman-Monteith equation is expressed as

$\lambda E=\frac{s(R n-G)+\rho_{\mathrm{a}} c_{\mathrm{p}} g_{\mathrm{a}}\left(e^{*}-e_{\mathrm{a}}\right)}{s+\gamma\left(1+\frac{g_{\mathrm{a}}}{g_{\mathrm{c}}}\right)}$

where $R n$ is the net radiation flux $\left(\mathrm{J} \mathrm{m}^{-2} \mathrm{~s}^{-1}\right), G$ is the storage heat flux $\left(\mathrm{J} \mathrm{m}^{-2} \mathrm{~s}^{-1}\right), g_{\mathrm{a}}$ and $g_{\mathrm{c}}$ are the aerodynamic and canopy conductances $\left(\mathrm{m} \mathrm{s}^{-1}\right)$, and $e^{*}$ and $e_{\mathrm{a}}$ are, respectively, the saturation (at air temperature) and actual vapor pressure of the atmosphere. The other variables have already been defined. Note that although only $\operatorname{VPD}\left(e^{*}-e_{\mathrm{a}}\right)$ appears in the equation, Eq. 10 actually does use vapor pressure at the approximated canopy temperature in arriving at the driving force for transpiration because sensible heat transfer is an integral though implicit part of the equation.

The more accurate modeling of the transpiration flux through the Penman-Monteith equation avoids the drawbacks of using VPD in place of $\Delta e$ and leads to the second normalizing route, i.e., via a reference transpiration flux $\left(E_{\mathrm{o}}\right)$. In this case, the normalization of $\mathrm{WP}_{\mathrm{p}}^{\mathrm{c}}$ and $\mathrm{WP}_{\mathrm{b}}$ are expressed respectively through the following equations:

$\mathrm{WP}_{\mathrm{p}}^{\mathrm{c}, \otimes}=\frac{\sum_{i=1}^{n} A_{\mathrm{c}, \mathrm{i}}}{\sum_{i=1}^{n}\left(\frac{T_{\mathrm{c}}}{E_{\mathrm{o}}}\right)_{i}}$

$\mathrm{WP}_{\mathrm{b}}^{\otimes}=\frac{\text { Biomass }}{\sum_{i=1}^{n} t_{\mathrm{i}}\left(\frac{T}{E_{\mathrm{o}}}\right)_{i}}$

The summations are the same as those for Eqs. 7 and 8 . $A_{\mathrm{c}}, T_{\mathrm{c}}$ and $E_{\mathrm{o}}$ denote the quantity cumulated during each interval $i$. Again, for practical purposes an alternative form of Eq. 12 is often used, with $\overline{E_{\mathrm{o}}}$ being the mean daily $E_{\mathrm{o}}$ for the time interval $i$. With $t_{\mathrm{i}}$ varying, then the following equation must be used:

$\mathrm{WP}_{\mathrm{b}}^{\otimes}=\frac{\text { Biomass }}{\sum_{i=1}^{n}\left(\frac{T_{\mathrm{c}}}{E_{\mathrm{o}}}\right)_{i}}$

This approach was originally adopted by de Wit (1958), using pan evaporation in place of $E_{\mathrm{o}}$. Nowadays, it is suggested to use the reference crop evapotranspiration as $E_{\mathrm{o}}$ and calculated according to the PenmanMonteith equation (Eq. 10), as rearranged and recommended by FAO, Irrigation and Drainage Paper no. 56 (Allen et al. 1998).

Various experimental works have shown the normalization of $\mathrm{WP}_{\mathrm{b}}$ by $E_{\mathrm{o}}$ to be more robust than the normalization by VPD (e.g., Azam-Ali et al. 1994; Clover et al. 2001; Steduto and Albrizio 2005). After all, this approach has already been used very successfully for normalizing crop evapotranspiration, yielding the crop coefficients $\left(K_{\mathrm{c}}\right)$ used worldwide (Doorenbos and Pruit 1977). An example comparing normalization by VPD and by $E_{\mathrm{o}}$ is shown in Fig. 7a, b, respectively, for the same crops depicted in Fig. 4 through 6. Another example comparing the two ways of normalization is given in Fig. 8a, b. In these figures, it is easily seen that compared to normalization by VPD, normalization by $E_{\mathrm{o}}$ gave results that are more unified and hence should be more useful in applications across a range of conditions differing in evaporative demand. 

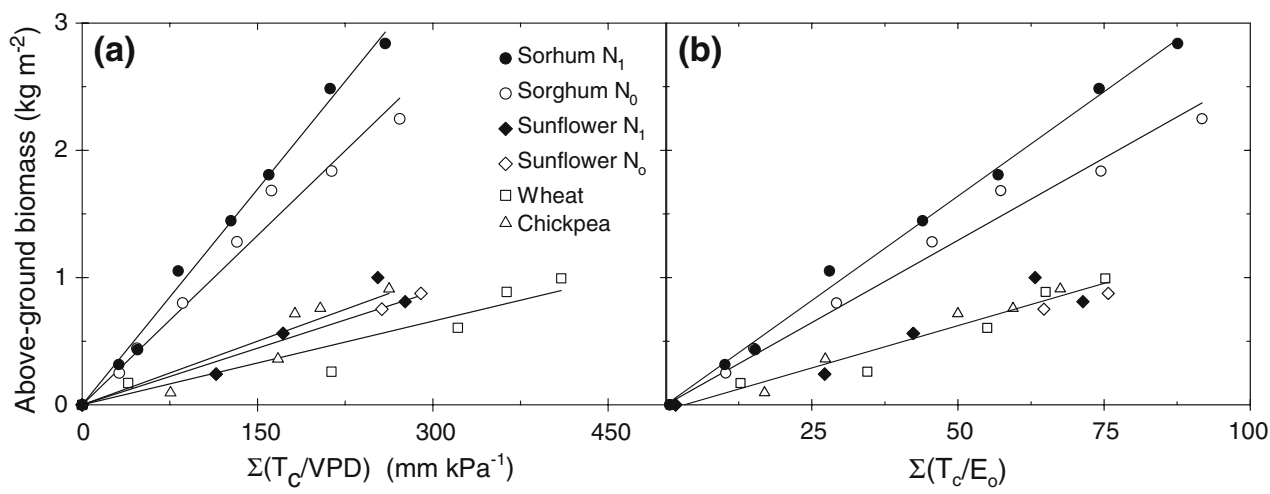

Fig. 7 Relationship between aboveground biomass and cumulative crop transpiration when normalized a for day-time saturation vapor pressure deficit of the atmosphere (VPD) and $\mathbf{b}$ for daily reference-crop evapotranspiration $\left(E_{\mathrm{o}}\right)$. Data from the same sets of experiments as those depicted in Figs. 3 through 5, but with only pre-anthesis data for sunflower. Data refer to period from June to September, from May to August, from
March to May, and from April to June, for sorghum, sunflower, wheat and chickpea, respectively. Note the normalization for $E_{\mathrm{o}}$ caused the grouping of all $c_{3}$ species on a line with a single slope $\left(13.4 \mathrm{~g} \mathrm{~m}^{-2}\right)$. Slopes for Sorghum are 25 and $32.9 \mathrm{~g} \mathrm{~m}^{-2}$ for the unfertilized $\left(N_{\mathrm{o}}\right)$ and fertilized $\left(N_{1}\right)$ treatments, respectively. Redrawn from Steduto and Albrizio (2005)

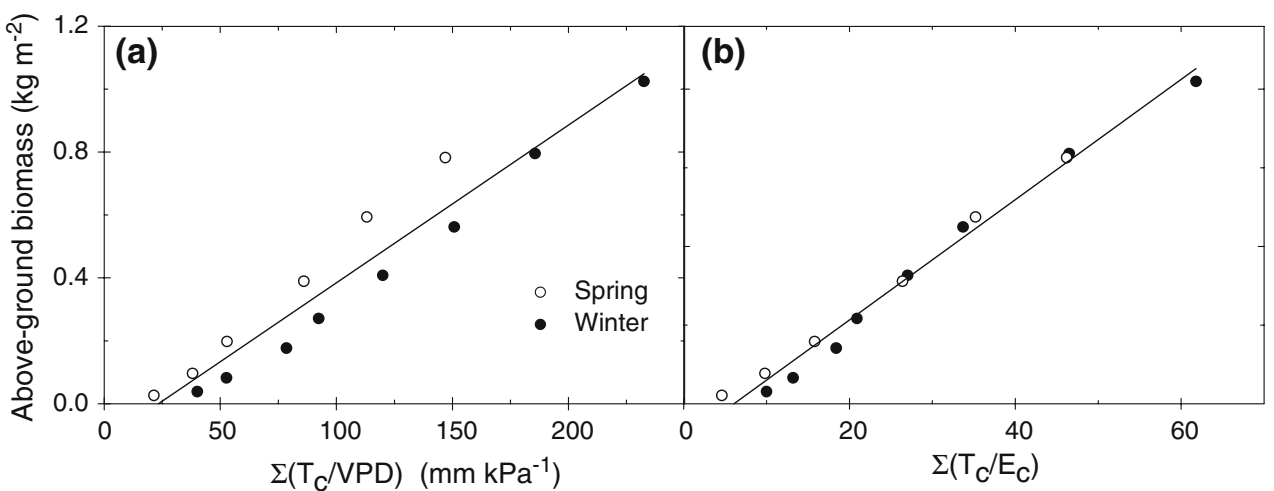

Fig. 8 Relationship between aboveground biomass and cumulative crop transpiration: when normalized a for daily saturation vapor pressure deficit of the atmosphere (VPD) and b for reference-crop evapotranspiration $\left(E_{\mathrm{o}}\right)$. Data were obtained in Cordoba, Spain, on sunflower planted in the field either in winter

In our studies, the advantage of normalizing by $E_{\mathrm{o}}$ was evident when comparing data obtained on crops grown in atmospheric environments that differed in temperature, vapor pressure, and radiation regimes (i.e., winter vs. spring). When crops were grown in one location under similar environments but in different years, in one comparison there were no obvious differences between the two normalization procedures (T.C. Hsiao, unpublished).

\section{Normalization for different atmospheric $\mathrm{CO}_{2}$ concentrations}

Similar to the $\mathrm{WP}_{\mathrm{b}}$ normalization for different atmospheric evaporative demands, also the normalization of $\mathrm{WP}_{\mathrm{b}}$ for different atmospheric $\mathrm{CO}_{2}$ concentrations requires a reference status, in this case of $\mathrm{CO}_{2}$ con-
(December-February) or spring (March-April). Note the normalization for $E_{\mathrm{o}}$ caused the grouping of the data for the winter and spring plantings to coalesce more along the regression line having a slope of $17.5 \mathrm{~g} \mathrm{~m}^{-2}$. Derived from the original data of Soriano et al. (2004)

centration. This approach was alluded to by Tanner and Sinclair (1983), and was more fully developed through the analysis by Hsiao (1993).

The conceptual points of departure are (1) the leaf gas-exchange processes formulation under steady-state conditions, as expressed by Eqs. 1 and 2, and (2) the accumulated evidence indicating a strong tendency of the ratio $c_{\mathrm{i}} / c_{\mathrm{a}}(=\alpha)$ to remain constant (Hsiao and Jackson 1999), attributed to the evolutionary adaptation of plants to environment and consistent with the theory of optimal stomatal behavior in water use (Cowan 1982).

Expressing $c_{\mathrm{i}}$ as a function of $c_{\mathrm{a}}$ (i.e., $c_{\mathrm{i}}=\alpha c_{\mathrm{a}}$ ) and substituting in Eq. 3, yields

$\mathrm{WP}_{\mathrm{p}}=0.625(1-\alpha) \frac{c}{\Delta w}$ 
In view of the conservative behavior of $\alpha$, it is advantageous to express the $\mathrm{WP}_{\mathrm{p}}$ under a different $\mathrm{CO}_{2}$ concentration on a relative basis, i.e., as compared to its value under a reference $\mathrm{CO}_{2}$ concentration. Indicating with subscript "o" the $\mathrm{WP}_{\mathrm{p}}$ of the reference situation, the $\mathrm{WP}_{\mathrm{p}}$ of any new situation relative to the reference situation is expressed as

$$
\frac{\mathrm{WP}_{\mathrm{p}}}{\mathrm{WP}_{\mathrm{p}, \mathrm{o}}}=\frac{0.625(1-\alpha)}{0.625\left(1-\alpha_{\mathrm{o}}\right)} \frac{c_{\mathrm{a}}}{\Delta w} \frac{\Delta w_{\mathrm{o}}}{c_{\mathrm{a}, \mathrm{o}}}
$$

That, after cancellation (with $\alpha \cong \alpha_{\mathrm{o}}$ ), reduces to

$$
\begin{aligned}
\frac{\mathrm{WP}_{\mathrm{p}}}{\mathrm{WP}_{\mathrm{p}, \mathrm{o}}} & =\frac{c_{\mathrm{a}}}{c_{\mathrm{a}, \mathrm{o}}} \frac{\Delta w_{\mathrm{o}}}{\Delta w} \\
\therefore \quad \mathrm{WP}_{\mathrm{p}} & =\mathrm{WP}_{\mathrm{p}, \mathrm{o}} \frac{c_{\mathrm{a}}}{c_{\mathrm{a}, \mathrm{o}}} \frac{\Delta w_{\mathrm{o}}}{\Delta w}
\end{aligned}
$$

Equation 16 indicates that $\mathrm{WP}_{\mathrm{p}}$ for any situation is the product of the reference $\mathrm{WP}_{\mathrm{p}, \mathrm{o}}$, the $c_{\mathrm{a}}$ ratio, and the $\Delta w$ ratio; and it represents the first paradigm equation (Hsiao 1993) for investigating changes in water productivity under different $\mathrm{CO}_{2}$ concentrations (e.g., elevated future $\mathrm{CO}_{2}$ ). It should also be recognized that, in order to normalize the value of $\mathrm{WP}_{\mathrm{p}}$, it is necessary to know its reference value $\left(\mathrm{WP}_{\mathrm{p}, \mathrm{o}}\right)$. Presently there is not yet a common reference $c_{\mathrm{a}}$, and researchers are likely to choose a particular $\mathrm{WP}_{\mathrm{p}, \mathrm{o}}$ for their specific crop at their own convenience (e.g., $\mathrm{Xu}$ and Hsiao 2004). Progress in analyzing WP would be facilitated if $c_{\mathrm{a}}$ of a particular time (e.g., summer) and year (e.g., 2000) measured at a particular location (e.g., Mauna Loa Observatory, Hawaii) is chosen as a common reference.

Even though Eq. 15 was derived from equations describing the gas-exchange of single leaves, $\mathrm{Xu}$ and Hsiao (2004) have shown that the equation predicted quite well the hour-by-hour changes in $\mathrm{WP}_{\mathrm{p}}^{\mathrm{c}}$ of a cotton canopy in the open field. Apparently, the scaling up from leaf to canopy did not require any modification of Eq. 15. This is likely the result of Eq. 15 expressing $\mathrm{WP}_{\mathrm{p}}$ relative to $\mathrm{WP}_{\mathrm{p}, \mathrm{o}}$, as up scaling from leaf to canopy should be identical or very similar for different situations regardless of environmental conditions (Xu and Hsiao 2004).

Although Eq. 16 remains valid when applied to canopies, as long as $\alpha$ stays the same, additional considerations are required when extending it to biomass. At aggregated canopy scale, biomass can be expressed as

Biomass $=c\left(\sum_{i=1}^{n}\left(A_{\mathrm{c}}\right)_{i}-\sum_{i=1}^{n}\left(R_{\mathrm{c}}\right)_{i}\right)$ where, $C$ is the biomass per unit of carbon dioxide for a given composition; $A_{\mathrm{c}}$ is the net crop assimilation during day-time and $R_{\mathrm{c}}$ is the crop dark respiration during night-time; both $A_{\mathrm{c}}$ and $R_{\mathrm{c}}$ are integrated over the number of days $(n)$ during which the biomass is produced.

Since the relationship between $R_{\mathrm{c}}$ and $A_{\mathrm{c}}$ tends to remain conservative, as previously indicated in "Photosynthetic water productivity-canopy scale" and "From net carbon gain to biomass", by setting $\beta$ as the ratio of $R_{\mathrm{c}} / A_{\mathrm{c}}$, so that $R_{\mathrm{c}}=\beta A_{\mathrm{c}}$, and substituting into Eq. 17, one obtains the following:

$$
\begin{aligned}
\text { Biomass } & =C\left(\sum_{i=1}^{n}\left(A_{\mathfrak{c}}\right)_{\mathrm{i}}-\beta \sum_{i=1}^{n}\left(A_{\mathrm{c}}\right)_{i}\right) \\
\therefore \quad \text { Biomass } & =C(1-\beta) \sum_{i=1}^{n}\left(A_{\mathrm{c}}\right)_{i}
\end{aligned}
$$

Using Eq. 18, the biomass water productivity $\left(\mathrm{WP}_{\mathrm{b}}\right)$ can then be expressed as

$\mathrm{WP}_{\mathrm{b}}=\frac{\text { Biomass }}{\sum_{i=1}^{n}\left(T_{\mathrm{c}}\right)_{i}}=\frac{C(1-\beta) \sum_{i=1}^{n}(A)_{i}}{\sum_{i=1}^{n}(T)_{i}}$

In view of the conservative behavior of $\beta$, also in this case it is advantageous to express the change of $\mathrm{WP}_{\mathrm{b}}$ on a relative basis, i.e., its value under new $\mathrm{CO}_{2}$ as compared to the reference value under the reference $\mathrm{CO}_{2}$ concentration. Therefore, in analogy to Eq. 15, and using the same subscript and superscript symbols, we can derive

$$
\begin{aligned}
& \frac{\mathrm{WP}_{\mathrm{b}}}{\mathrm{WP}_{\mathrm{b}, \mathrm{o}}}=\frac{\text { Biomass }}{\sum_{i=1}^{n}\left(T_{\mathrm{c}}\right)_{i}} \frac{\sum_{i=1}^{n}\left(T_{\mathrm{c}, \mathrm{o}}\right)_{i}}{\text { Biomass }_{\mathrm{o}}} \\
& \quad \Rightarrow \frac{\mathrm{WP}_{\mathrm{b}}}{\mathrm{WP}_{\mathrm{b}, \mathrm{o}}}=\frac{C(1-\beta)}{C\left(1-\beta_{\mathrm{o}}\right)} \frac{\sum_{i=1}^{n}\left(A_{\mathrm{c}}\right)_{i}}{\sum_{i=1}^{n}\left(T_{\mathrm{c}}\right)_{i}} \frac{\sum_{i=1}^{n}\left(T_{\mathrm{c}, \mathrm{o}}\right)_{i}}{\sum_{i=1}^{n}\left(A_{\mathrm{c}, \mathrm{o}}\right)_{i}}
\end{aligned}
$$

That, after cancellation (with $\beta_{\mathrm{n}} \cong \beta_{\mathrm{o}}$ ) and rearrangement, reduces to

$$
\frac{\mathrm{WP}_{\mathrm{b}}}{\mathrm{WP}_{\mathrm{b}, \mathrm{o}}}=\frac{\sum_{i=1}^{n}\left(A_{\mathrm{c}}\right)_{i}}{\sum_{i=1}^{n}\left(A_{\mathrm{c}, \mathrm{o}}\right)_{i}} \frac{\sum_{i=1}^{n}\left(T_{, o}\right)_{i}}{\sum_{i=1}^{n}(T)_{i}}=\frac{\sum_{i=1}^{n}\left(\mathrm{WP}_{\mathrm{p}}^{\mathrm{c}}\right)_{i}}{\sum_{i=1}^{n}\left(\mathrm{WP}_{\mathrm{p}, \mathrm{o}}^{\mathrm{c}}\right)_{i}}
$$

Equation 20 indicates that the relative change in $\mathrm{WP}_{\mathrm{p}}$ is the product of the $A_{\mathrm{c}}$ ratio by $T_{\mathrm{c}}$ ratio, which corresponds to the $\mathrm{WP}_{\mathrm{p}}^{\mathrm{c}}$ ratio of the gas-exchange at canopy level over the number of days $(n)$.

Since, as mentioned before, the same equation applies when up-scaling from leaf to canopy gas-exchange, Eq. 20 can be rewritten in analogy to Eq. 16 as 
$\mathrm{WP}_{\mathrm{b}}=\mathrm{WP}_{\mathrm{b}, \mathrm{o}} \frac{\sum_{i=1}^{n}\left(c_{\mathrm{a}}\right)_{i}}{\sum_{i=1}^{n}\left(c_{\mathrm{a}, \mathrm{o}}\right)_{i}} \frac{\sum_{i=1}^{n}\left(\Delta \mathrm{w}_{\mathrm{o}}\right)_{i}}{\sum_{i=1}^{n}(\Delta \mathrm{w})_{i}}$

Equation 21 indicates that $\mathrm{WP}_{\mathrm{b}}$ for any situation (e.g., elevated $\mathrm{CO}_{2}$ ) is the product of the reference value $\left(\mathrm{WP}_{\mathrm{b}, \mathrm{o}}\right)$ times the $c_{\mathrm{a}}$ ratio and times the $\Delta w$ ratio (as is for Eq. 16), cumulated over the same number of days during which the biomass is produced.

To normalize the biomass water productivity value under any atmospheric $\mathrm{CO}_{2}$ concentration (of the past or of the future) to the reference value $\left(\mathrm{WP}_{\mathrm{b}, \mathrm{o}}\right)$ it is just a matter of rearranging the same equation as follows:

$\mathrm{WP}_{\mathrm{b}, \mathrm{o}}=\mathrm{WP}_{\mathrm{b}} \frac{\sum_{i=1}^{n}\left(c_{\mathrm{a}, \mathrm{o}}\right)_{i}}{\sum_{i=1}^{n}\left(c_{\mathrm{a}}\right)_{i}} \frac{\sum_{i=1}^{n}(\Delta \mathrm{w})_{i}}{\sum_{i=1}^{n}\left(\Delta \mathrm{w}_{\mathrm{o}}\right)_{i}}$

Data with sufficient details to test the validity of Eqs. 21 and 22 are rare. In one study, cotton plants were grown in pots in controlled environment chambers under normal, $1.5 \times$ normal and $2 \times$ normal air $\mathrm{CO}_{2}$ concentrations and their $\mathrm{WP}_{\mathrm{b}}$ was determined. Other than the differences in $\mathrm{CO}_{2}$, the chambers were the same in environment. As expected, the results (Table 1) show that the measured $\mathrm{WP}_{\mathrm{b}}$ was positively correlated with the level of $c_{\mathrm{a}}$. Designating the normal air $\mathrm{CO}_{2}$ concentration $(360 \mathrm{ppm})$ as the reference situation, i.e., its $c_{\mathrm{a}}$ as $c_{\mathrm{a}, \mathrm{o}}$ and its $\Delta w$ as $\Delta w_{\mathrm{o}}$, the normalized $\mathrm{WP}_{\mathrm{b}}\left(\mathrm{WP}_{\mathrm{b}, \mathrm{o}}\right)$ was calculated for the two elevated $\mathrm{CO}_{2}$ treatments. It is seen in the fifth column of Table 1 that the resultant $\mathrm{WP}_{\mathrm{b}, \mathrm{o}}$ was nearly identical in value compared to the measured $\mathrm{WP}_{\mathrm{b}}$ for the reference situation. The $\mathrm{WP}_{\mathrm{b}}$ of the elevated $\mathrm{CO}_{2}$ treatments was then predicted with Eq. 21 from the designated $\mathrm{WP}_{\mathrm{b}, \mathrm{o}}\left(3.93 \mathrm{~g} \mathrm{~kg}^{-1}\right)$ the known $c_{\mathrm{a}}$ ratio, and the $\Delta w$ ratio. The results (Table 1, last column) show that $\mathrm{WP}_{\mathrm{b}}$ at elevated $\mathrm{CO}_{2}$ predicted by Eq. 21 agreed closely with the measured values. The close agreement (within 2\%) suggests strongly that Eqs. 15 and 21 adequately account for all the important variables that affect biomass water productivity at least in cotton. Nonetheless, it is desirable to obtain more data of this nature to test further the validity of Eqs. 15, 21 and 22, especially for other crop species.

Equations 16 and 21 are fundamental and should hold regardless of whether plants are $\mathrm{C}_{3}$ or $\mathrm{C}_{4}$, and under various sets of changes in environmental conditions (i.e., not only $\mathrm{CO}_{2}$ ). This normalizing approach for different atmospheric $\mathrm{CO}_{2}$ concentrations is expected to be the most valuable and robust one since it is based on the conservative behavior of $\alpha\left(c_{\mathrm{i}} / c_{\mathrm{a}}\right)$ and $\beta\left(R_{\mathrm{c}} / A_{\mathrm{c}}\right)$, most likely the consequence of natural evolution and adaptation of plants in resources-use optimization.

The normalizations for evaporative demand and for atmospheric $\mathrm{CO}_{2}$ have been treated separately, although Eq. 22 has the potential to be used for the purpose of integrated normalization. That is because it expresses $\mathrm{WP}_{\mathrm{b}, \mathrm{o}}$ as a function of both the $c_{\mathrm{a}}$ ratio needed to normalize for $\mathrm{CO}_{2}$ and the $\Delta w$ ratio that is a part of Eqs. 7, 8, or 9 for the normalization for evaporative demand. Unfortunately in practice the data demanded by Eq. 22 are not readily available for crops grown in open fields or greenhouses. This problem will be elaborated on in "Uncertainties in the normalization for atmospheric $\mathrm{CO}_{2}$ ", where a practical approach to normalize for the two key variables will be given.

Some important implications of normalizing biomass water productivity are clear. First, it allows the comparison of WP data across the globe on equal footing, after accounting for differences due to variations in evaporative demand of the climate, and in atmospheric carbon dioxide concentration when applicable. Such comparisons will reveal more definitively the intrinsic

Table 1 Measured biomass water productivity $\left(\mathrm{WP}_{\mathrm{b}}\right)$, normalized biomass water productivity $\left(\mathrm{WP}_{\mathrm{b}, \mathrm{o}}\right)$, and predicted $\mathrm{WP}_{\mathrm{b}}$ of cotton plants grown in pots under three levels of air $\mathrm{CO}_{2}$ concentration in controlled environmental chambers

\begin{tabular}{llllll}
\hline $\begin{array}{l}\text { Nominal } c_{\mathrm{a}} \\
(\mathrm{ppm})\end{array}$ & $\begin{array}{l}r^{2} \text { for } \mathrm{WP}_{\mathrm{b}} \\
\text { determination }\end{array}$ & $\Delta w / \Delta w_{\mathrm{o}}$ & $\begin{array}{l}\mathrm{WP}_{\mathrm{b}} \text { measured } \\
\left(\mathrm{g} \mathrm{kg}^{-1}\right)\end{array}$ & $\begin{array}{l}\mathrm{WP}_{\mathrm{b}, \mathrm{o}} \text { calculated (Eq. 22) } \\
\left(\mathrm{g} \mathrm{kg}^{-1}\right)\end{array}$ & $\begin{array}{l}\mathrm{WP}_{\mathrm{b}} \text { predicted (Eq. 21) } \\
\left(\mathrm{g} \mathrm{kg}^{-1}\right)\end{array}$ \\
\hline 360 & 0.998 & 1 & 3.93 & 3.93 & - \\
540 & 0.997 & 0.967 & 5.15 & 3.87 & 5.23 \\
720 & 0.996 & 0.934 & 7.17 & 3.85 & 7.32 \\
\hline
\end{tabular}

Measured $\mathrm{WP}_{\mathrm{b}}$ was determined from plots of biomass produced versus cumulative transpiration by linear regression, and the coefficients of determination are given in the table as $r^{2}$. Designating the normal air $\mathrm{CO}_{2}$ concentration (360 ppm) as the reference situation, biomass water productivity of the plants grown at either 540 or $720 \mathrm{ppm} \mathrm{CO}_{2}$ were normalized using Eq. 22 with the $c_{\mathrm{a}}$ and $\Delta w$ of the reference situation. Predicted $\mathrm{WP}_{\mathrm{b}}$ was calculated using Eq. 21 with $\mathrm{WP}_{\mathrm{b}}$ of the reference situation $\left(\mathrm{WP}_{\mathrm{b}, \mathrm{o}}=3.93 \mathrm{~g} \mathrm{~kg}^{-1}\right)$. Since chamber conditions were kept the same from day to day, summation called for in Eq. 21 and 22 was not necessary and the overall $c_{\mathrm{a}}$ and $\Delta w$ were used in the calculation. Plants were grown over a 43 -day period under about $700 \mu \mathrm{mol} \mathrm{m}^{-2} \mathrm{~s}^{-1}$ of PAR, 27/20 $\mathrm{P}^{\circ}$ and $45 /$ $80 \%$ relative humidity for the day and night periods. Periodically shoot biomass was harvested while water lost by transpiration for each period was measured by water balance. Soil surface was covered to eliminate evaporation. Air $\mathrm{CO}_{2}$ was measured intermittently to obtain an overall $c_{\mathrm{a}}$ that was slightly different from the nominal set values of the chamber. Foliage temperature data used to calculate $\Delta w$ were obtained in a separate experiment under very similar conditions. Derived from Hsiao and Xu (2000b) 
properties of the crop or the management practices that alter WP. Most importantly, normalized WP will provide a head start in knowing the WP at a new location or new time period when $\mathrm{CO}_{2}$ concentration is different, whether in the future or in the past. For example, Eq. 21 will permit the prediction of $\mathrm{WP}_{\mathrm{b}}$ once the $\mathrm{CO}_{2}$ concentration for a situation is known and the vapor pressure gradient $(\Delta w)$ is estimated.

\section{Some unresolved issues}

Up to this point we have focused on the basics and the apparently more straight forward relationships, even though there are possible complicating effects in some of our assumptions, and uncertainty over the degree of variation in $\alpha$ with respect to some environmental features. At least four issues deserve more attention and are briefly discussed here.

\section{Effects of air humidity and water stress on $\alpha$}

The fact that stomata of many species open less under large $\Delta w$ is well known (Schulze and Hall 1982). It has been shown (Morison 1987) that $\alpha$ changes in close association with stomatal changes caused by $\Delta w$. So as $\Delta w$ changes dynamically in the open field, $\alpha$ would be expected to change dynamically as the result. Fortunately, the empirically determined relationship between $\alpha$ and $\Delta w$ appears to be simple, with $\alpha$ decreasing nearly linearly as $\Delta w$ increases (Morison 1987; Xu and Hsiao 2004). Thus, the pattern of $\alpha$ values could be estimated from the pattern of $\Delta w$ using their linear empirical relationship. $\mathrm{Xu}$ and Hsiao (2004) have shown that by adjusting $\alpha$ according to $\Delta w$ with the linear relationship, their theoretical model was able to predict the diurnal changes in canopy $\mathrm{WP}_{\mathrm{p}}$ of cotton in the open field. Without the adjustment the prediction deviated markedly from the measured $\mathrm{WP}_{\mathrm{p}}$ for a substantial part of the day. For the estimation of WP over the long term, however, how to obtain the most valid integration of $\alpha$ remains to be worked out.

Studies based on carbon isotope discrimination have shown (e.g., Johnson and Tieszen 1993) or inferred (e.g., Acevedo 1993) a reduction in $\alpha$ under water deficits. These results are probably confounded, however, by the likely stomatal response to $\Delta w$. Under conditions of water deficit, transpiration is lower due to reduced stomatal conductance; consequently the foliage is warmer and $\Delta w$ is higher. The reduced $\alpha$ under water deficit may be the result of this change in $\Delta w$, and not a direct response to water deficit. In addition, much of the isotope data were obtained by stressing the plants in pot cultures where stress develops much faster than in the field. Slow adjustment to stress appears to be needed for $\alpha$ to remain constant.

\section{Genotypic variation in $\alpha$}

The evidence for differences in $\alpha$ among genotypes is mostly based on carbon isotope discrimination (Farquhar et al. 1989), a measure widely used in efforts to breed for higher WP and resistance to drought (see: Acevedo 1993; Wright et al. 1993; Condon et al. 2004, for review). Different genotypes of various $C_{3}$ crop species exhibited under similar conditions only limited differences (e.g., 10\%) in $\alpha$ when well watered. The probable exceptions are genotypes of peanut, which exhibited apparently larger differences in $\alpha$ as inferred from carbon isotope discrimination data (Wright et al. 1993). The significant efforts devoted to breeding for lower $\alpha$ and higher WP have been constrained because, in most cases, less isotope discrimination (lower $\alpha$ ) is associated with slower biomass production and lower yield when water supply is not severely limiting (Acevedo 1993; Condon et al. 2004). The work of Rebetzke et al. (2002) in wheat demonstrates the extensive efforts necessary to make only marginal yield improvements under water deficit conditions using carbon isotope discrimination as a selection tool.

In all cases described above where $\alpha$ has values significantly different from the values of 0.7 for $\mathrm{C}_{3}$ and 0.4 for $\mathrm{C}_{4}$ noted in "Photosynthetic water productivity-leaf scale", but not changing dynamically, it is simply a matter of using the correct $\alpha$ value in Eq. 5 in making assessments of WP. In cases of normalizing for different $\mathrm{CO}_{2}$ concentrations using Eq. 22, or its equivalent rearrangement of Eq. 16, if $\alpha$ is significantly different between the reference situation and the actual situation, it is necessary to substitute $(1-\alpha) c_{\mathrm{a}}$ in place of $c_{\mathrm{a}}$, for both situations.

Effects of nitrogen nutrition and changing shoot-root ratio on the constancy of $\mathrm{WP}_{\mathrm{b}}$

Two other situations may introduce some variation in WP. On the one hand, it has been shown that $\alpha$ remains nearly constant over a range of $\mathrm{N}$ nutrition (Wong et al. 1979; Fig. 2). Nevertheless, when the $\mathrm{N}$ deficiency is severe, the decrease in leaf photosynthesis has been associated with a decrease in $\mathrm{WP}_{\mathrm{b}}$. Crop plants grown under limited $\mathrm{N}$ adjust primarily their leaf area before their intrinsic photosynthetic rate is affected (Sinclair and Horie 1989). Thus, one would expect that 
$\mathrm{WP}_{\mathrm{b}}$ would tend to decrease in low $\mathrm{N}$ supply situations only in cases of quite severe $\mathrm{N}$ deficiency.

The known response of a shift in assimilate partitioning toward the root system relative to the shoot caused by water deficits (Hsiao and Xu 2000b) could induce an apparent change in $\mathrm{WP}_{\mathrm{b}}$ in situations where water stress increases in severity with time. This is because a larger and larger proportion of the assimilated carbon would be going to the roots and not to the shoot, the part of the biomass normally harvested to measure $\mathrm{WP}_{\mathrm{b}}$. The maintenance of linearity over a substantial range of ET deficits in the myriad of published biomass-ET relations suggests, however, that this effect may not have a significant influence until water deficits become quite severe.

\section{Uncertainties in the normalization}

for atmospheric $\mathrm{CO}_{2}$

Still other uncertainties are in the normalization for $c_{\mathrm{a}}$. To normalize with Eqs. 15, 16 or 22, the ratio of $\mathrm{CO}_{2}$ as well as the ratio of water vapor concentration are required as input. Although the former may be taken as the measured value at the reference station or even the common value estimated for the world's atmosphere without much error, the latter $\left(\Delta w / \Delta \mathrm{w}_{\mathrm{o}}\right)$ is not simple to assess. Of course $w_{\mathrm{a}}$ is to be taken from weather data, but $w_{\mathrm{i}}$ and hence $\Delta w$ is a function of canopy temperature. Canopy temperature is best obtained by measurements; but data of measured canopy temperature over the weather dynamics of a growing season are rare. Canopy temperature can be estimated from weather data using the Penman-Monteith equation (Eq. 10), but detailed data on radiation, air temperature and humidity, and wind velocity, as well as canopy conductance $\left(g_{\mathrm{c}}\right)$ are required. At the present, $g_{\mathrm{c}}$ has been parameterized for use in the Penman-Monteith equation by Allen et al. (1998) to be constant at $14.3 \mathrm{~mm} \mathrm{~s}^{-1}$ (corresponding to $70 \mathrm{~s} \mathrm{~m}^{-1}$ in terms of resistance). Response of stomata of single leaves to changes in $c_{\mathrm{a}}$ is well known and has been characterized for a number of species (Morison 1987), but how changes in stomatal conductance scale up to changes in canopy conductance is still an open question (e.g., Baldocchi et al. 1991; Rochette et al. 1991), and well quantified data to facilitate the resolution are rare. The only certainty is that $g_{\mathrm{c}}$ would decrease with increases in atmospheric $\mathrm{CO}_{2}$.

In view of the reality that long time $\Delta w / \Delta w_{\mathrm{o}}$ data are not simple to obtain in the future and mostly noneexisting in the past, for practical purposes it is recommended for now that the following semi-empirical equation be used to normalize WP for atmospheric $\mathrm{CO}_{2}$ :

$\mathrm{WP}_{\mathrm{b}, \mathrm{o}}=\mathrm{WP}_{\mathrm{b}} \frac{c_{, o}}{c_{\mathrm{a}}} \times D$

where $c_{\mathrm{a}, \mathrm{o}}$ and $c_{\mathrm{a}}$ are the annual mean atmospheric $\mathrm{CO}_{2}$ concentrations measured at Mauna Loa Observatory (Hawaii), respectively for the reference year and for the year when $\mathrm{WP}_{\mathrm{b}}$ is determined; and $D$ is an empirical factor approximating the sum of $\Delta w$ to the sum of $\Delta w_{\mathrm{o}}$ ratio (Eq. 22). In theory and according to the $\Delta w / \Delta w_{\mathrm{o}}$ data in Table $1, D$ should decrease with increases in $c_{\mathrm{a}}$, and the decrease should be slight. As shown in Table 1 , the ratio appears to be reduced about $7 \%$ even for the case of a doubling in $\mathrm{CO}_{2}$. The data are for cotton grown in environmental chambers, where air turbulence (hence boundary layer conductance for sensible heat, which relates to canopy temperature) is less than in the open field. Therefore the $\Delta w$ ratio for cotton growing in the field under a doubling of $\mathrm{CO}_{2}$ should be even closer to 1.0. For now as a temporary measure, it is suggested that $D$ be approximated by the equation $D=a-b\left(c_{\mathrm{a}}-c_{\mathrm{a}, \mathrm{o}}\right)$, where $a=$ 1.0 , and $b=0.000138$. This relationship is based on the $\Delta w / \Delta w_{\mathrm{o}}$ data of Table 1 and assumes the $\Delta w$ ratio to be a linear function of the difference in $\mathrm{CO}_{2}$ concentration between the given and the reference situation. It also assumes, arbitrarily, that the effect of difference in $\mathrm{CO}_{2}$ on the ratio is reduced by $25 \%$ in the open field due to more turbulence. Implicit in the equation is the fact that the $c_{\mathrm{a}, \mathrm{o}}$ is taken to be $360 \mathrm{ppm}$. If the chosen $c_{\mathrm{a}, \mathrm{o}}$ is substantially higher or lower, the $b$ parameter should be reevaluated. Obviously, Eq. 23 can be rearranged to predict $\mathrm{WP}_{\mathrm{p}}$ at different $c_{\mathrm{a}}$.

It is emphasized that Eq. 23 can only be used to normalize for $\mathrm{CO}_{2}$ and does not account for any difference caused by evaporative demand of the air. That is because the $D$ factor is based on data obtained under the same environmental conditions in the growth chambers where air evaporative demand was constant. Consequently, for now it is recommended that biomass water productivity should first be normalized for atmospheric $\mathrm{CO}_{2}$ using Eq. 23, then the result be further normalized for evaporative demand using Eq. 13 (or Eq. 12). It is clear from this discussion that field data on canopy conductance and $\Delta w / \Delta w_{\mathrm{o}}$ under different air $\mathrm{CO}_{2}$ concentration and for different crops are badly needed for the development of a better $\mathrm{CO}_{2}$ normalization procedure in the future.

Yet, another practical question is how to settle on a reference state needed for $\mathrm{CO}_{2}$ normalization. Taking as a given that a common reference year or $c_{\mathrm{a}, \mathrm{o}}$ is 
agreed upon by the research community, there is still the question of agreeing on the value of $\mathrm{WP}_{\mathrm{b}, \mathrm{o}}$ of the given crop species, and on the associated $\Delta w_{\mathrm{o}}$, which is partly dependent on the specific weather record over the growing season. Obvious this can only be done by an organized effort, and substantial lead time is necessary to analyze the literature and developing new data before a unified base can be developed. As of now, it is likely that most researchers will choose the reference situation for their own convenience.

\section{Conclusions}

The above stepwise approach, from leaf to the whole canopy, has provided a conceptual and theoretical framework to explain the basis for the constancy of biomass water productivity $\left(\mathrm{WP}_{\mathrm{b}}\right)$. Following the pioneer work of de Wit (1958), Bierhuizen and Slatyer (1965), and Tanner and Sinclair (1983), the approach here added some new perspectives and new kinds of supporting data. Important is the fact that the scaling up does not involve complicated models and is underpinned at each level by theory and fundamentals, and by relevant data either recently published or new. Progress was made in the normalization for the two key climatic variables, evaporative demand and atmospheric $\mathrm{CO}_{2}$ concentration. We have justified by theory the use of reference ET $\left(E_{\mathrm{o}}\right)$ in place of air VPD for the evaporative demand normalization, and shown it to be superior by some experimental data. Equally significant is the normalization for atmospheric $\mathrm{CO}_{2}$ concentration, given its past changes and the certainty of its increase in the future. We have shown that, at the leaf level, because of the coordination of photosynthetic capacity and stomatal opening to maintain $c_{\mathrm{i}}$ nearly constant relative to $c_{\mathrm{a}}$, the normalized WP becomes a function of the external $\mathrm{CO}_{2}$ concentration. The $\mathrm{CO}_{2}$ normalization approach, tested with limited data to be also applicable at the canopy level, allows for the assessment of crop production under future climate scenarios.

As for temporal scales, canopy photosynthetic WP, though varying on a diurnal basis due to variations in evaporative demand and air $\mathrm{CO}_{2}$ concentration (Xu and Hsiao 2004), remains conservative when averaged over periods of days up to a season. Apparently the tight relation between photosynthesis and respiration contributed to that conservative behavior. The transition from photosynthetic to biomass WP depends on biomass composition. While the metabolic costs of biosynthesis do not vary significantly among crop species for vegetative structures, except for the difference between $\mathrm{C}_{3}$ and $\mathrm{C}_{4}$, it is strongly dependent on the protein and lipid content of fruits and seeds. Thus, normalized $\mathrm{WP}_{\mathrm{b}}$ should not differ much for crops of similar composition, although its value should decrease from cereals, to legumes, to oil crops. Recent experimental evidence presented above provides support for the theory and illustrates the conservativeness of normalized $\mathrm{WP}_{\mathrm{b}}$ under a wide variety of conditions.

Such features of normalized $\mathrm{WP}_{\mathrm{b}}$ offer an invaluable tool for modeling crop production as related to water supply and availability, providing an effective way of applying the normalized $\mathrm{WP}_{\mathrm{b}}$ values between different locations, climate and seasons. The robustness of $\mathrm{WP}_{\mathrm{b}}$, within the limits and uncertainties discussed above, paves the way for its use as the pivotal function driving the quantitative assessment of water-limited productivity. Another conservative parameter used for modeling crop productivity is radiation use efficiency (RUE). RUE, however, can remain variable even after normalizing for evaporative demand (Sinclair and Muchow 1999; Albrizio and Steduto 2005) and gives less consistent results in comparison to $\mathrm{WP}_{\mathrm{b}}$ in some cases (Steduto and Albrizio 2005).

An alternative use of $\mathrm{WP}_{\mathrm{b}}$ can be for the mapping of climatic zones as different classes of biomass water productivity and given cropping systems so that optimal spatial allocation could be developed to conserve the limited water resources. Moreover, $\mathrm{WP}_{\mathrm{b}}$ can be used as a simple measure of consumptive water use by crops. This can be achieved by dividing the weight of biomass (as dry matter) sampled from a cropped field by the pertinent $\mathrm{WP}_{\mathrm{b}}$ value, resulting in the crop transpiration cumulated up to the sampling time. In conjunction with estimates of soil evaporation, the overall cumulative evapotranspiration can be estimated as well. However, more field research is needed to broaden the application of constant $\mathrm{WP}_{\mathrm{b}}$, particularly under more extreme stresses, various rates of stress development, different level of mineral nutrition and air $\mathrm{CO}_{2}$ concentration, and diverse VPD and temperature regimes. Additionally, more extensive determination of $\mathrm{WP}_{\mathrm{b}}$ for crops having different biomass composition is needed.

As elaborated on in this paper, it is obvious that $\mathrm{WP}_{\mathrm{b}}$ of crops, being conservative, offers only limited opportunity for improving the productivity of the water consumed by crops. As briefly discussed, $\mathrm{WP}_{\mathrm{b}}$ can be raised by growing the crop under weather regimes of lower evaporative demand or by improving nitrogen nutrition. The potential improvements outside drastic modification of the environment (e.g., greenhouses), however, are quite limited. Raising $\mathrm{CO}_{2}$ concentration of the air offers a greater potential in theory, and can 
be achieved with current technology in protected cultivation such as in plastic tunnels and glasshouses. For production in the open field, enrichment with $\mathrm{CO}_{2}$ of the air surrounding the crop, though tested from time to time, is not a foreseeable practical possibility. On the other hand, the current relentless rise in atmospheric $\mathrm{CO}_{2}$ with time is certainly to raise $\mathrm{WP}_{\mathrm{b}}$ of crops in the future. For example, $50 \%$ increase in $c_{\mathrm{a}}$ would raise $\mathrm{WP}_{\mathrm{b}}$ by slightly less than $50 \%$ according to Eq. 21.

Given the conservative behavior of $\mathrm{WP}_{\mathrm{b}}$, and its relatively narrow range of variation between genotypes, it seems that promising research directions for its improvement can come only from some genetic breakthroughs which would change the intrinsic carboxylation and respiration capacities of plants. Such breakthroughs are extremely difficult to achieve since the natural evolution of species has apparently already optimized complex adaptation mechanisms to natural resource use. In any case, the time frame for such breakthroughs to occur would be quite long, in decades at least.

In considering the overall productivity of water, the exchange of transpirational water for biomass production $\left(\mathrm{WP}_{\mathrm{b}}\right)$ is only one of the many sequential steps starting from water supplied either as rain or as delivered water leading to the final crop yield. The other steps encompass the engineering and management aspects of water storage, conveyance and irrigation application, water retention in the soil root zone and extraction by the crop, soil evaporation, and the partition of biomass between the vegetative residue and the yield part of the crop. Though $\mathrm{WP}_{\mathrm{b}}$ is conservative, the other steps offer many possibilities to improve the overall water productivity. This is the subject of a companion paper in this issue (Hsiao et al. 2007).

Acknowledgement The authors thank the Land and Water Division of FAO, United Nations, for providing support in the research and preparation of this paper. The work of TCH has been partly funded by the US Department of Energy grant DeFG03-93-ER-6187, US Department of Agriculture NRICGP grant 99-35306-7793, and the CGIAR Water and Food Challenging Program through ICARDA. The authors are also grateful to Dr. Rossella Albrizio for sharing most of her experimental dataset. The help of Dr. Yoshiko Kasugi in obtaining and analyzing the data in Table 1 is much appreciated.

\section{References}

Acevedo E (1993) Potential of carbon isotope discrimination as a selection criterion in barley breeding. In: Ehleringer JR, Hall AE, Farquhar GD (eds) Stable isotopes and plant carbon-water relations. Academic, San Diego, pp 399-417
Albrizio R, Steduto P (2003) Photosynthesis, respiration and conservative carbon use efficiency of four field grown crops. Agric For Meteorol 116:19-36

Albrizio R, Steduto P (2005) Resource use efficiency of fieldgrown sunflower, sorghum, wheat and chickpea. I. Radiation use efficiency. Agric For Meteorol 130:254-268

Allen RG, Pereira LS, Raes D, Smith M (1998) Crop evapotranspiration. Guidelines for computing crop water requirements (Irrigation and drainage paper 56). Food and Agriculture Organization, Rome

Amthor JS (1989) Respiration and crop productivity. Springer, New York, $215 \mathrm{p}$

Amthor JS (1995) Higher plant respiration and its relationships with Photosynthesis. In: Schulze ED, Caldwell MM (eds) Ecophysiology of photosynthesis. Springer, Berlin, pp 71101

Angus JF, Hasegawa S, Hsiao TC, Liboon SP, Zandstra HG (1983) The water balance of post-monsoonal dryland crops. J Agric Sci (Camb) 101:699-710

Arkley J (1963) Relationships between plant growth and transpiration. Hilgardia 34:559-584

Asseng S, Hsiao TC (2000) Canopy $\mathrm{CO}_{2}$ assimilation, energy balance, and water use efficiency of an alfalfa crop before and after cutting. Field Crops Res 67:191-206

Azam-Ali SN, Crout NMJ, Bradley RG (1994) Perspectives in modelling resource capture by crops. In: Monteith JL, Unsworth MH, Scott RK (eds) Resource capture by crops. Proceedings of the 52nd University of Nottingham Eastern School. Nottingham University Press, Nottingham, pp 125 148

Baldocchi DD, Luxmoore RJ, Hatfield JL (1991) Discerning the forest from the trees: an essay on scaling canopy conductance. Agric For Meteorol 54:197-226

Bierhuizen JF Slatyer OR (1965) Effect of atmosphere concentration of water vapor and $\mathrm{CO}_{2}$ in determining transpiration-photosynthesis relationships of cotton leaves. Agric Meteorl 2:259-270

Biscoe PV, Scott RK, Monteith JL (1975) Barley and its environment. III. Carbon budget of the stand. J Appl Ecol $12: 269-293$

Björkman O (1981) The response of photosynthesis to temperature. In: Grace J, Ford ED, Jarvis PG (eds) Plants and their atmospheric environment. Blackwell, Oxford, London, Edinburgh, Boston, Melbourne, pp 273-301

Bolaños JA, Hsiao TC (1991) Photosynthesis and respiratory chracterization of field grown tomato. Photosynth Res 28:21-32

Briggs IJ, Shantz HL (1913a) The water requirement of plants: I. Investigation in the Great Plains in 1910 and 1911. USDA Bureau Plant Industry Bull, $284 \mathrm{p}$

Briggs IJ, Shantz HL (1913b) The water requirement of plants: II. A review of the literature. USDA Bureau Plant Industry Bull, $285 \mathrm{p}$

Brouwer R (1983) Functional equilibrium: sense or nonsense? Neth J Agric Sci 31:335-348

Charles-Edwards DA (1982) Physiological determinants of crop growth. Academic, Sydney, $158 \mathrm{p}$

Cheng W, Sims DA, Luo Y, Coleman JS, Johnson DW (2000) Photosynthesis, respiration and net primary production of sunflower stands in ambient and elevated atmospheric $\mathrm{CO} 2$ concentrations: an invariant NPP:GPP ratio? Glob Change Biol 6:931-941

Clover GRG, Jaggard KW, Smith HG, Azam-Ali SN (2001) The use of radiation interception and transpiration to predict the yield of healthy, droughted and virus-infected sugar beet. $\mathbf{J}$ Agric Sci 136:169-178 
Condon AG, Richards RA, Rebetzke GJ, Farquhar GD (2004) Breeding for high water-use efficiency. J Exp Bot 55:24472460

Cowan IR (1982) Regulation of water use in relation to carbon gain in higher plants. In: Lange OL, Nobel PS, Osmod CB, Zigler H (eds) Physiological plant ecology II. Ecycl plant physiol, NS, vol 12 B. Springer, Berlin, pp 589-613

Doorenbos J, Pruit WO (1977) Crop water requirements (Irrigation and drainage paper 24). Food and Agriculture Organization, Rome, $144 \mathrm{p}$

Farquhar GD, Richards RA (1984) Isotopic composition of plant carbon correlates with water-use efficiency of wheat genotypes. Aust J Plant Physiol 11:539-552

Farquhar GD, Sharkey TD (1982) Stomatal conductance and photosynthesis. Ann Rev Plant Physiol 33:317-345

Farquhar GD, Ehleringer JR, Hubick KT (1989) Carbon isotope discrimination and photosynthesis. Ann Rev Plant Physiol Plant Mol Biol 40:503-537

Fereres E, Goldhamer DA, Parson LR (2003) Irrigation water management of horticultural crops. HortScience 38(5):10361042

Garcia R, Kanemasu ET, Blad BL, Bauer A, Hatfield JL, Major DJ, Reginato RJ, Hubbard KG (1988) Interception and use efficiency of light in winter wheat under different nitrogen regimes. Agric For Meteorol 44:175-186

Gifford RM (1995) Whole plant respiration and photosynthesis of wheat under increased $\mathrm{CO} 2$ concentration and temperature: long-term vs. short-term distinctions for modelling. Glob Change Biol 1:385-396

Hanks RJ (1974) Model for predicting as influenced by water use. Agron J 66:660-665

Hanks JR (1983) Yield and water-use relationships: an overview. In: Taylor HM, Jordan WA, Sinclair TR (eds) Limitations to efficient water use in crop production. ASA, Madison, pp 393-411

Hirasawa T, Wakabayashi K, Touya S, Ishihara K (1995) Stomatal response to water deficits and abscisic acid in leaves of sunflower plants (Helianthus annuus L.) grown under different conditions. Plant Cell Physiol 36:955-964

Hsiao TC (1993) Effects of drought and elevated $\mathrm{CO}_{2}$ on plant water use efficiency and productivity. In Jackson MD, Black CR (eds) Global environmental change. Interacting stresses on plants in a changing climate. NATO ASI series. Springer, New York, pp 435-465

Hsiao TC, Bradford KJ (1983) Physiological consequences of cellular water deficits. In: Taylor HM, Jordan WA, Sinclair TR (eds) Limitations to efficient water use in crop production. ASA, Madison, pp 227-265

Hsiao TC, Jackson RB (1999) Interactive effects of water stress and elevated $\mathrm{CO}_{2}$ on growth, photosynthesis, and water use efficiency. In: Luo Y, Mooney HA (eds) Carbon dioxide and environmental stress. Academic, New York, pp 3-31

Hsiao TC, Xu L-K (2000a) Sensitivity of growth of roots vs. leaves to water stress: biophysical analysis and relation to water transport. J Exp Bot 51:1595-1616

Hsiao TC, Xu L-K (2000b). Predicting water use efficiency of crops. Acta Hortucult 537:199-206

Hsiao TC, Steduto P, Fereres E (2007) A systematic and quantitative approach to improve water use efficiency in agriculture. Irrig Sci (this issue)

Johnson RC, Tieszen LL (1993) Carbon isotope discrimination, water relations, and gas exchange in temperate grass species and accessions. In: Ehleringer JR, Hall AE, Farquhar GD (eds) Stable isotopes and plant carbon-water relations. Academic, San Diego, pp 281-296
Lambers H (1987) Growth, respiration, exudation and symbiotic association: the fate of carbon tranlocated to roots. In: Gregory PJ, Lake JV, Rose DA (eds) Root development and function. Cambridge University Press, London, pp 123 145

Landsberg JJ, Waring RH, Coops NC (2003) Performance of the forest productivity model 3-PG applied to a wide range of forest types. For Ecol Manage 172:199-214

Lhomme JP (1991) The concept of canopy resistance: historical survey and comparison of different approaches. Agric For Meteorol 54:227-240

Louwerse W (1980) Effects of $\mathrm{CO}_{2}$ concentration and irradiance on the stomatal behavior of maize, barley, and sunflower plants in the field. Plant Cell Environ 3:391-398

Meek DW, Hatfield JL, Howell TA, Idso SB, Reginato RJ (1984) A generalized relationship between photosynthetically active radiation and solar radiation. Agron J 76:939-945

Monteith JL (1977) Climate and the efficiency of crop production in Britain. Philos T R Soc Lond B 281:277-294

Monteith JL (1980) The deveopment and extension of Penmans' evaporation formula. In: Hillel D (ed) Application of soil physics. Academic, New York, pp 247-253

Monteith JL (1984) Consistency and convenience in the choice of units for agricultural science. Exp Agric 20:105-117

Monteith JL (1993) The exchange of water and carbon by crops in a mediterranean climate. Irrig Sci 14:85-91

Morison JIL (1987) Intercellular $\mathrm{CO}_{2}$ concentration and stomatal response to $\mathrm{CO}_{2}$. In: Zeiger E, Farquhar GD, Cowan IR (eds) Stomatal function. Stanford University Press, Stanford, pp 229-251

Norman JM (1979) Modelling the complete crop canopy. In: Barfield BJ, Gerber JF (eds) Modification of the aerial environment of crops. ASAE, St. Joseph, pp 249-277

Osmond CB, Winter K, Ziegler H (1982) Functional significance of different pathways of $\mathrm{CO}_{2}$ fixation in photosynthesis. In: Lange OL, Nobel PS, Osmond CB, Zeigler H (eds) Physiological plant ecology II. Water relations and carbon assimilation. Encyclopedia of plant physiology, new series 12B. Springer, Berlin, pp 479-547

Oweis T, Zhang H, Pala M (2000) Water use efficiency of rainfed and irrigated bread wheat in a Mediterranean environment. Agron J 92(2):231-238

Paw U KT, Gao W (1988) Applications of solutions to non-linear energy budget equations. Agric For Meteorol 43:121-145

Pearcy RW (1983) Physiological consequences of cellular water deficits: non-stomatal inhibition of photosynthesis by water stress. In: Taylor HM, Jordan WA, Sinclair TR (eds) Limitations to efficient water use in crop production. ASA, Madison, pp 277-287

Penman HL (1948) Natural evaporation from open water, bare soil and grass. Proc R Soc Lond Ser A 193:120-146

Penning de Vries FWT, Brunsting AHM, van Laar HH (1974) Products, requirements and efficiency of biosynthesis: a quantitative approach. J Theor Biol 45:339-377

Penning de Vries FWT, Van Laar HH, Chardon MCM (1983) Bioenergetics of growth of seeds, fruits, and storage organs. In: Potential productivity of field crops under different environments. International Rice Research Institute, Manila, pp 37-60

Rebetzke GJ, Condon AG, Richards RA, Farquhar GD (2002) Selection for reduced carbon isotope discrimination increases aerial biomass and grain yield of rainfed bread wheat. Crop Sci 42:739-745

Rochette P, Pattey E, Desjardins RL, Dwyer LM, Stewart DW, Dube PA (1991) Estimation of maize (Zea mays L.) canopy 
conductance by scaling up leaf stomatal conductance. Agric For Meteorol 54:241-261

Schulze DE, Hall AE (1982) Stomatal responses, water loss and $\mathrm{CO}_{2}$ assimilation rates of plant. In: Lange OL, Nobel PS, Osmond CB, Ziegler H (eds) Physiological plant ecology. II Encyclopedia of plant physiology, 12B. Springer, Berlin, pp $181-230$

Seckler D, Amarasinghe U, Molden D, De Silva R, Barker R (1998) World water demand and supply, 1990 to 2025: scenarios and issues. International Water Management Institute Research Report 19, Colombo, Sri Lanka

Sinclair TR, Horie T (1989) Leaf nitrogen, photosynthesis, and crop radiation use efficiency: a review. Crop Sci 29:90-98

Sinclair TR, Muchow RC (1999) Radiation use efficiency. Adv Agron 65:215-265

Soriano MA, Orgaz F, Villalobos FJ, Fereres E (2004) Efficiency of water use of early plantings of sunflower. Eur J Agron 21:465-476

Stanhill G (1981) The size and significance of differences in the radiation balance of plants and plant communities. In: Grace J, Ford EP, Jarvis PJ (eds) Plant and their atmospheric environment. Balckwell, Oxford, pp 57-73

Stanhill G (1986) Water use efficiency. Adv Agron 39:53-85

Steduto P (1996) Water use efficiency. In: Pereira LS, Feddes RA, Gilley JR, Lesaffre B (eds) Sustainability of irrigated agriculture. NATO ASI series E: applied sciences. Kluwer, Dordrecht, pp 193-209

Steduto P, Albrizio R (2005) Resource-use efficiency of fieldgrown sunflower, sorghum, wheat and chickpea. II Water use efficiency and comparison with radiation use efficiency. Agric For Meteorol 130:269-281

Steduto P, Katerji N, Puertos-Molina H, Ünlü M, Mastrosilli M, Rana G (1997) Water use efficiency of sweet sorghum under water stress conditions. Gas-exchange investigations at leaf and canopy scales. Field Crops Res 54:221-234

Steduto P, Albrizio R, Giorio P, Sorrentino G (2000) Gasexchange response and stomatal and non-stomatal limitations to carbon assimilation of sunflower under salinity. Environ Exp Bot 44:243-255

Stewart JI (1972) Prediction of water production functions and associated irrigation programs to minimize crop yield and profit losses due to limited water. PhD Thesis, University of California Davis. University Microfils\#73-16, 934 p
Stöckle CO, Donatelli M, Nelson R (2003) CropSyst, a cropping systems simulation model. Eur J Agron 18:289-307

Tanner CB (1981) Transpiration efficiency of potato. Agron J 73:59-64

Tanner CB, Sinclair TR (1983) Efficient water use in crop production: research or re-search? In: Taylor HM, Jordan WA, Sinclair TR (eds) Limitations to efficient water use in crop production. ASA, Madison, pp 1-27

Taylor HM (1983) Managing root systems for efficient water use: an overview. In: Taylor HM, Jordan WA, Sinclair TR (eds) Limitations to efficient water use in crop production. ASA, Madison, pp 87-113

Varlet-Grancher C, Gosse G, Chartier M, Sinoquet H, Bonhomme R, Allirand JM (1989) Mis ou point: rayonnement solaire absorbé ou intercepté par un couvert végétal. Agronomie 9:419-439

Von Caemmerer S, Farquhar GD (1981) Some relationships between the biochemistry of photosynthesis and the gas exchange of leaves. Planta 153:376-387

Whitfield DM, Connor DJ, Hall AJ (1989) Carbon dioxide balance of sunflower subjected to water stress during grainfilling. Filed Crops Res 20:65-80

de Wit CT (1958) Transpiration and crop yields. Versl. Landbouwk. Onderz. 64.6 Inst. Biol. Chem. Res. On Field Crops and Herbage, Wageningen, The Netherlands

de Wit CT, Brouwer R, and Penning de Vries FWT (1970) The simulation of photosynthetic systems. In: Setlik (ed) Prediction and measurement of photosynthetic productivity. Pudoc, Wageningen, pp 47-70

Wong SC, Cowan IR, Farquhar GD (1979) Stomatal conductance correlates with photosynthetic capacity. Nature 282:424-426

Wright GC, Hubick KT, Farquhar GD, Rao RCN (1993) Genetic and environmental variation in transpiration efficiency and its correlation with carbon isotope discrimination and specific leaf area in peanut. In: Ehleringer JR, Hall AE, Farquhar GD (eds) Stable isotopes and plant carbon-water relations. Academic, San Diego, pp 247-267

Xu L-K, Hsiao TC (2004) Predicted vs. measured photosynthetic water use efficiency of crops stands under dynamically changing field environments. J Exp Bot 55:2395-2411 